\title{
Spatial and Spatiotemporal Pattern Analysis of Coconut Lethal Yellowing in Mozambique
}

\author{
F. Bonnot, H. de Franqueville, and E. Lourenço
}

First author: CIRAD, UPR Etiologie Dépérissements, F-34398 Montpellier, France; second author: CIRAD, UPR Génétique palmier, F-34398 Montpellier, France; and third author: GRUPO MADAL, Avenida Julius Nyerere, N. 48 CP 17, Quelimane, Mozambique. Accepted for publication 20 November 2009.

\section{ABSTRACT}

Bonnot, F., de Franqueville, H., and Lourenço, E. 2010. Spatial and spatiotemporal pattern analysis of coconut lethal yellowing in Mozambique. Phytopathology 100:300-312.

Coconut lethal yellowing (LY) is caused by a phytoplasma and is a major threat for coconut production throughout its growing area. Incidence of LY was monitored visually on every coconut tree in six fields in Mozambique for 34 months. Disease progress curves were plotted and average monthly disease incidence was estimated. Spatial patterns of disease incidence were analyzed at six assessment times. Aggregation was tested by the coefficient of spatial autocorrelation of the $\beta$-binomial distribution of diseased trees in quadrats. The binary power law was used as an assessment of overdispersion across the six fields. Spatial autocorrelation between symptomatic trees was measured by the $B B$ join count statistic based on the number of pairs of diseased trees separated by a specific distance and orientation, and tested using permutation methods. Aggregation of symptomatic trees was detected in every field in both cumulative and new cases. Spatiotemporal patterns were analyzed with two methods. The proximity of symptomatic trees at two assessment times was investigated using the spatiotemporal $B B$ join count statistic based on the number of pairs of trees separated by a specific distance and orientation and exhibiting the first symptoms of LY at the two times. The semivariogram of times of appearance of LY was calculated to characterize how the lag between times of appearance of LY was related to the distance between symptomatic trees. Both statistics were tested using permutation methods. A tendency for new cases to appear in the proximity of previously diseased trees and a spatially structured pattern of times of appearance of LY within clusters of diseased trees were detected, suggesting secondary spread of the disease.
The cultivation of coconut (Cocos nucifera L.) is threatened in many parts of its growing area by lethal yellowing (LY) disease, which has destroyed hundreds of thousands of trees worldwide (20,34-36). Symptoms of LY include premature fruit drop, blackening of newly opened inflorescences, ascending yellowing of the leaves, and tree death (21). Infected trees usually die within 5 to 10 months after the appearance of the first symptom (8). LY is caused by a phytoplasma (30) and, according to Howard (15), in Florida the phytoplasma is transmitted by a leafhopper, Myndus crudus Van Duzee (Cixiidae). In Africa, the vector remains unknown $(28,29)$.

LY was first reported in the Cayman Islands around 1830. LY then spread throughout the Caribbean region to Haiti, the Dominican Republic, Cuba, Jamaica, and then Florida. The disease reached the Yucatan peninsula of Mexico during the 1980s (3) and was reported in Honduras in 1996 by Ashburner et al. (1). In West Africa, LY was reported around 1930 in Togo (Kaincopé disease) (2), southeastern Ghana (Cape St Paul Wilt), Cameroon (Kribi disease) (9), and Nigeria (Akwa disease) (10). In East Africa, LY occurs in Tanzania, Kenya, and Mozambique (23). In Mozambique, LY first appeared in an area close to Tanzania where LY was observed in 1912 in the district of Mtwara (34,35). Most cases of LY are now concentrated in the southern area of Quelimane.

Most epidemiological analyses of LY have focused on the temporal development of disease or only on qualitative descriptions of its spatial pattern $(8,20,35,36)$. There are few quantitative

Corresponding author: F. Bonnot; E-mail address: francois.bonnot@cirad.fr

doi:10.1094/PHYTO-100-4-0300

(C) 2010 The American Phytopathological Society analyses $(11,13)$. Although sequential analyses of spatial patterns of LY at different times of assessment have been published (26), to our knowledge there has been no analysis of spread both in space and over time.

Different methods can be used to quantify the spatial and spatiotemporal patterns of disease for plants or trees grown in a regular lattice. Methods based on the distribution of diseased trees in quadrats of various sizes and shapes can be used to characterize aggregation in disease incidence (17). Methods based on twodimensional distance class analysis make it possible to characterize the relative location of diseased plants at the same time period and to detect deviations from spatial randomness and clustering of diseased plants $(14,25)$. When plants are monitored over time, it is possible to characterize the location of newly diseased plants in relation to previously diseased plants and to test dependence between the two sets of plants. Spatiotemporal distance class analysis methods (24) have frequently been used to analyze epidemiological data collected at different times. More general methods based on join counts can also be used to analyze spatial or spatiotemporal autocorrelation of binary data (4). Geostatistics provides methods to measure spatial dependence between quantitative observations separated by a specific distance (6). When the observed variable is the time of appearance of a disease, relations between spatial and temporal development of the disease can be established.

The main goal of this study was to integrate observations made over time in six fields of coconut trees infected by LY in Mozambique to improve our understanding of how the disease spreads within fields. The primary objectives were to (i) describe the temporal progress of disease, (ii) characterize spatial patterns of LY-infected trees in commercial coconut plantations, and (iii) characterize how the lag between times of appearance of LY was related to the distance between symptomatic trees. 


\section{MATERIALS AND METHODS}

Fields. Data were collected from six fields in the commercial coconut plantation of Madal company in Mozambique planted with Malayan dwarf $\times$ local tall hybrids between 1987 and 1992 (Table 1). The distance between rows was $7.80 \mathrm{~m}$ and the distance between trees within each row was $9 \mathrm{~m}$. The number of trees per field at the beginning of the observation period was 784 to 1,463 . Fields had irregular boundaries and heterogeneous shapes, and some trees were missing before the first assessment for unknown reasons (Fig. 1). Locations of fields A to F followed an approximate direction of northeast to southwest and the distances between fields were $22 \mathrm{~km}$ (A to B), $0.5 \mathrm{~km}$ (B to C), $4 \mathrm{~km}$ (C to D), $1.4 \mathrm{~km}$ (D to E), and $26 \mathrm{~km}$ ( $\mathrm{E}$ to $\mathrm{F}$ ).

Data collection. Fields were monitored from September 1999 to June 2002. Time of assessment was measured in months and ranged from 1 (September 1999) to 34 (June 2002). The time interval between two assessments was 1,2, or 3 months (Table 2). Incidence data were collected in each field by assessing every tree for visual symptoms of LY and classifying it as healthy or

TABLE 1. Location of fields and field characteristics for examining the spatial and temporal dynamics of coconut lethal yellowing incidence in Mozambique

\begin{tabular}{|c|c|c|c|c|c|c|c|c|}
\hline Field & Site and field ID & Location & No. of trees & Planting year & Length $(\mathrm{m})^{\mathrm{a}}$ & Width $(\mathrm{m})^{\mathrm{a}}$ & Geographic coordinates & Azimuth $^{b}$ \\
\hline A & Mingano C3 & $\begin{array}{l}\text { Quelimane } \\
\text { Inhangulue (Marrobune) }\end{array}$ & 1,463 & 1991 & 441 & 257 & $\begin{array}{l}17^{\circ} 59^{\prime} 57^{\prime \prime} \mathrm{S} \\
36^{\circ} 58^{\prime} 29^{\prime \prime} \mathrm{E}\end{array}$ & $160^{\circ}$ \\
\hline B & Tumbuine A11 & Inhanssunge & 1,126 & 1990 & 891 & 156 & $\begin{array}{l}18^{\circ} 04^{\prime} 24^{\prime \prime} \mathrm{S} \\
36^{\circ} 47^{\prime} 31^{\prime \prime} \mathrm{E}\end{array}$ & $300^{\circ}$ \\
\hline $\mathrm{C}$ & Tumbuine A14 & Inhanssunge & 1,223 & 1990 & 873 & 218 & $\begin{array}{l}18^{\circ} 04^{\prime} 30^{\prime \prime} \mathrm{S} \\
36^{\circ} 47^{\prime} 17^{\prime \prime} \mathrm{E}\end{array}$ & $300^{\circ}$ \\
\hline D & Matulune I4 & Inhanssunge & 1,366 & 1990 & 792 & 156 & $\begin{array}{l}18^{\circ} 05^{\prime} 44^{\prime \prime} \mathrm{S} \\
36^{\circ} 45^{\prime} 25^{\prime \prime} \mathrm{E}\end{array}$ & $300^{\circ}$ \\
\hline $\mathrm{F}$ & Micaune Barra A9 & Micaune & 1,028 & 1992 & 522 & 195 & $\begin{array}{l}18^{\circ} 19^{\prime} 51^{\prime \prime} \mathrm{S} \\
36^{\circ} 42^{\prime} 53^{\prime \prime} \mathrm{E}\end{array}$ & $140^{\circ}$ \\
\hline
\end{tabular}

a Length and width of the rectangle parallel to the rows and containing the field.

${ }^{b}$ Angle in degrees, measured clockwise, between the north base line and a perpendicular to the rows.

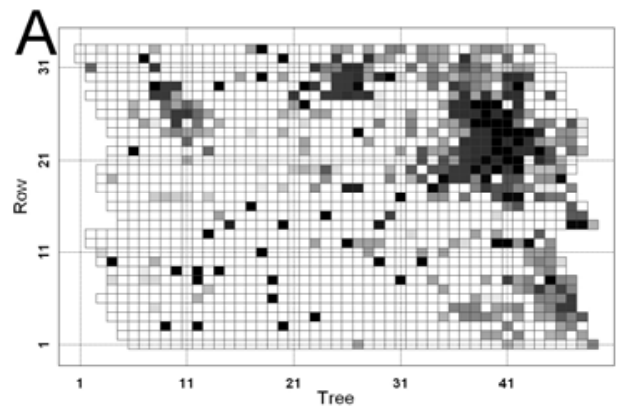

B
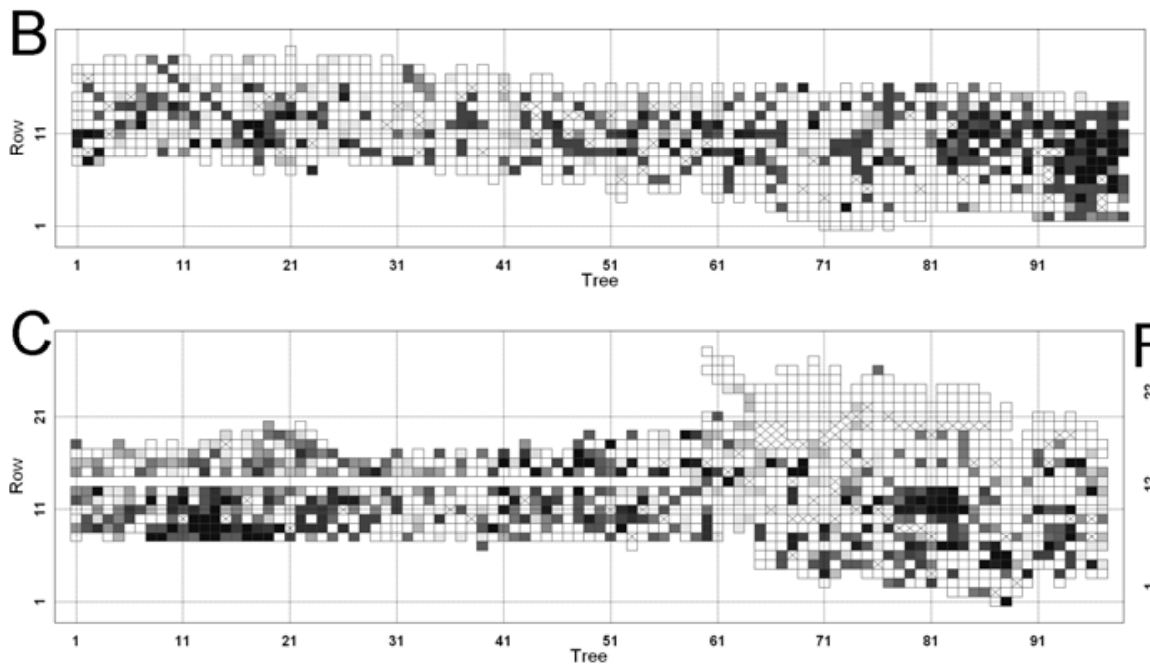

Time of appearance of lethal yellowing (month)

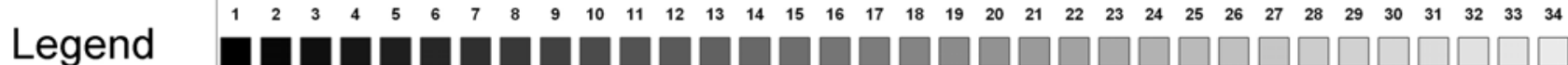

Asymptomatic tree
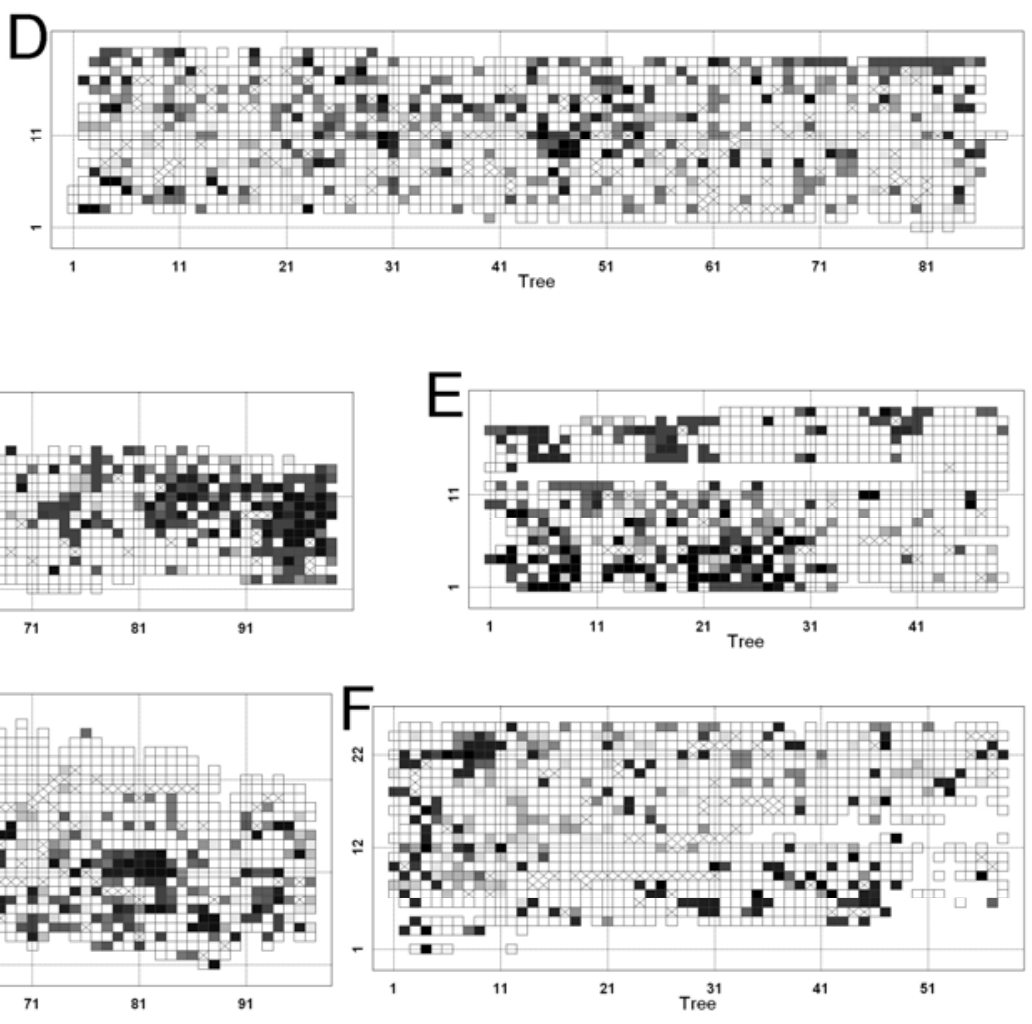

Missing tree

Fig. 1. Maps of six fields (A to F) of coconut palm infected by lethal yellowing in Mozambique between September 1999 (month 1) and June 2002 (month 34 ). Each rectangle symbolizes one tree. 
diseased each time the field was assessed. Depending on the analyses, individual monthly assessments were used or were dropped in favor of 6-month assessments in months 4, 10, 16, 22, 28 , and 34 due to the nature of disease progress. Because fields were located in a commercial plantation, trees infected by LY were systematically removed after first observation of the symptoms. Various studies have shown that the removal of infected trees can limit the spread of the disease $(8,11)$. Removed trees were considered to be diseased in the analyses after they had been cut down.

Temporal progress of disease. Cumulative incidence and monthly incidence of LY in each field were plotted against time. Cumulative incidence was defined as the ratio of the number of diseased (and, therefore, removed) trees to the total number of trees counted at the beginning of the observation period (19). Monthly incidence between times $t_{1}$ and $t_{2}$ was defined as the ratio of the number of newly diseased trees between $t_{1}$ and $t_{2}$ to the number of asymptomatic trees at time $t_{1}$, divided by the lag $t_{2}-t_{1}$. The average monthly incidence over the period of 34 months was calculated by averaging the monthly incidences weighted by the lags $t_{2}-t_{1}$.

Spatial analysis. Distribution of diseased trees per quadrat. Distributional analyses were performed on quadrats of varying sizes to determine cluster sizes. Aggregation in disease incidence was characterized by fitting the binomial and $\beta$-binomial distributions to the observed frequencies of diseased trees in quadrats (17). Each field was partitioned successively into quadrats of $r$ rows by $s$ trees, with $r$ and $s$ varying from 1 to 6 . The 1-by-1 quadrat type was excluded, so that 35 quadrat sizes were analyzed. For each quadrat size, only quadrats with $>80 \%$ of trees not removed at the beginning of the observation period were retained for the analysis. The within-quadrat degree of aggregation was quantified by the $\beta$-binomial parameter $\kappa$, a measure of intraclass correlation (12). This parameter was estimated by fitting a generalized linear model to the data under the hypothesis that each observed count of diseased trees per quadrat is the result of a $\beta$-binomial random variable with a varying initial number $n_{\mathrm{i}}$ of trees in quadrat $i$ (38). Maximum likelihood was used to estimate $\kappa$, and a likelihood ratio test was performed to determine if the $\beta$-binomial distribution fitted the data better than the binomial, indicating that the spatial pattern was aggregated (22). A $\chi^{2}$ goodness-of-fit test was used to check whether the $\beta$ binomial distribution provided a good fit to the data. The effect of orientation and shape was tested by investigating the relationship between the length/width ratio of the quadrat type and the parameter $\kappa$.

The binary power law was used to characterize the relationship between heterogeneity and disease incidence observed in the monthly ratings of disease in the six fields (16). The binary power law is often written in its linearized form as $\ln \left(V_{o b s}\right)=\ln (A)+$ $b \ln \left(V_{b i n}\right)$, where $V_{o b s}$ is the observed variance of diseased trees within quadrats and $V_{b i n}=n p(1-p)$ would be the expected variance if data followed a binomial distribution, where $n$ is the number of trees per quadrat and $p$ is mean disease incidence. When $A=1$ and $b=1$, the spatial pattern is random and can be described by the binomial distribution. When $A>1$ and $b=1$, disease is aggregated and the level of aggregation is independent of $p$. When $A>1$ and $b>1$, the degree of aggregation varies systematically with $p$. The parameters $\ln (A)$ and $b$ were estimated by linear regression, and the equality of $\ln (A)$ to 0 and $b$ to 1 was tested by a $t$ test using the estimated parameters and their standard deviations. The initial numbers of trees per quadrat was not constant; therefore, the mean value of plants per quadrat was used to estimate $V_{b i n}$ and $V_{o b s}(5)$.

Join count analysis. Consider a lattice of trees where symptomatic plants are coded $B$ and asymptomatic plants are coded $W$. Two plants at sites $s_{\mathrm{i}}$ and $s_{\mathrm{j}}$ are separated by a vector, or spatial lag, $\overrightarrow{\mathrm{h}}$, determined by the distance $d$ between plants and an angular direction $\theta$ (the directions $\theta$ and $\theta+180^{\circ}$ are considered equivalent). To determine whether events in all pairs of sites separated by $\overrightarrow{\mathrm{h}}$ are spatially autocorrelated, the number of $B B$, $W W$, and $B W$ joins for pairs separated by $\overrightarrow{\mathrm{h}}$ are counted and compared with the expected numbers of joins of the same category under the null hypothesis $\mathrm{H}_{0}$ of no spatial autocorrelation. We used the $B B$ join count to test whether diseased trees separated by $\overrightarrow{\mathrm{h}}$ were spatially autocorrelated. Instead of calculating the $B B$ join count for each existing spatial lag $\vec{h}$ between trees, classes were defined from a restricted set of spatial lags $\overrightarrow{\mathrm{h}}_{1}, \overrightarrow{\mathrm{h}}_{2}, \ldots, \overrightarrow{\mathrm{h}}_{\mathrm{L}}$ and each pair of trees was allocated to the class $C\left(\overrightarrow{\mathrm{h}}_{i}\right)$ defined by the closest spatial lag $\overrightarrow{\mathrm{h}}_{i}$ in distance and orientation. The $B B\left(\overrightarrow{\mathrm{h}}_{i}\right)$ join count was then calculated for each class $C\left(\overrightarrow{\mathrm{h}}_{i}\right)$. The spatial lags $\overrightarrow{\mathrm{h}}_{1}, \overrightarrow{\mathrm{h}}_{2}, \ldots, \overrightarrow{\mathrm{h}}_{\mathrm{L}}$ were defined by combining predetermined distances $(d)$ and orientations $(\theta)$ in order to compute spatial correlograms. Predetermined distances were multiples of $9 \mathrm{~m}$, corresponding to the distance between two adjacent trees within the row. Because we wanted more accuracy near the origin of the correlogram, the predetermined distances were chosen at increasing intervals and were fixed at 9 to $90 \mathrm{~m}$ by increments of $9 \mathrm{~m}$, at 108 to $180 \mathrm{~m}$ by increments of $18 \mathrm{~m}$, and at $216 \mathrm{~m}$ and further by increments of $36 \mathrm{~m}$. Angular directions were $0^{\circ}, 45^{\circ}, 90^{\circ}$, and $135^{\circ}$ measured clockwise, direction $0^{\circ}$ being perpendicular to the rows. Omnidirectional correlograms depending only on distance and not on orientation were also computed.

Under the hypothesis of spatial randomness, the expected value of $B B\left(\overrightarrow{\mathrm{h}}_{i}\right)$ is

$$
E\left[B B\left(\overrightarrow{\mathrm{h}}_{i}\right)\right]=A\left(\overrightarrow{\mathrm{h}}_{i}\right) \frac{n_{1}\left(n_{1}-1\right)}{n(n-1)}
$$

where $A\left(\overrightarrow{\mathrm{h}}_{i}\right)$ is the number of pairs of trees in the class $C\left(\overrightarrow{\mathrm{h}}_{i}\right), n$ is the total number of trees in the field, and $n_{1}$ is the number of

TABLE 2. Number of newly infected trees by coconut lethal yellowing in six fields in Mozambique over 4 years

\begin{tabular}{|c|c|c|c|c|c|c|c|c|c|c|c|c|c|c|c|c|c|c|c|c|c|c|c|c|c|c|}
\hline \multirow[b]{3}{*}{ Month $^{\mathrm{a}}$} & \multicolumn{24}{|c|}{ Date } & \multirow[b]{4}{*}{$\operatorname{Inf}^{\mathrm{b}}$} & \multirow[b]{4}{*}{ No. ${ }^{c}$} \\
\hline & \multicolumn{4}{|c|}{1999} & \multicolumn{12}{|c|}{2000} & \multicolumn{6}{|c|}{2001} & \multicolumn{2}{|c|}{2002} & & \\
\hline & Sep & Oct & Nov & Dec & Jan & Feb & Mar & Apr & May & Jun & Jul & Aug & Sep & Oct & Nov & Dec & Feb & Apr & Jun & Aug & Oct & Dec & Mar & Jun & & \\
\hline Field & 1 & 2 & 3 & 4 & 5 & 6 & 7 & 8 & 9 & 10 & 11 & 12 & 13 & 14 & 15 & 16 & 18 & 20 & 22 & 24 & 26 & 28 & 31 & 34 & & \\
\hline A & 58 & 12 & $\ldots$ & 1 & 3 & $\ldots$ & 36 & 33 & 6 & $\ldots$ & 21 & 9 & $\ldots$ & 8 & $\ldots$ & 11 & 52 & 16 & 85 & 25 & 6 & 7 & 19 & 14 & 422 & 1,463 \\
\hline B & $\ldots$ & $\ldots$ & 59 & $\ldots$ & 20 & 12 & $\ldots$ & 17 & 96 & 60 & $\ldots$ & 32 & $\ldots$ & 12 & $\ldots$ & 19 & 8 & 23 & 4 & 8 & 8 & 4 & 20 & 38 & 440 & 1,126 \\
\hline $\mathrm{C}$ & $\ldots$ & $\ldots$ & 67 & $\ldots$ & 33 & $\ldots$ & 35 & 10 & 42 & $\ldots$ & 40 & 48 & $\ldots$ & 30 & $\ldots$ & 50 & 27 & 26 & 16 & 20 & 22 & 15 & 25 & 65 & 571 & 1,223 \\
\hline $\mathrm{D}$ & 17 & 12 & 2 & 5 & 17 & 27 & $\ldots$ & 1 & 27 & 31 & $\ldots$ & 18 & 11 & $\ldots$ & 21 & $\ldots$ & 102 & 22 & 22 & 10 & 10 & 7 & 27 & 49 & 438 & 1,366 \\
\hline $\mathrm{E}$ & 50 & 7 & 1 & 4 & 2 & 32 & $\ldots$ & 9 & 28 & 33 & $\ldots$ & $\ldots$ & 33 & $\ldots$ & 13 & $\ldots$ & 9 & 13 & 5 & 10 & 6 & 9 & 1 & 9 & 274 & 784 \\
\hline $\mathrm{F}$ & 13 & 7 & $\ldots$ & $\ldots$ & 55 & 33 & $\ldots$ & 12 & 2 & 2 & $\ldots$ & 2 & 8 & $\ldots$ & 2 & $\ldots$ & 30 & 8 & 8 & 22 & 11 & 8 & 31 & 19 & 273 & 1,028 \\
\hline Total & 138 & 38 & 129 & 10 & 130 & 104 & 71 & 82 & 201 & 126 & 61 & 109 & 52 & 50 & 36 & 80 & 228 & 108 & 140 & 95 & 63 & 50 & 123 & 194 & 2,418 & 6,990 \\
\hline
\end{tabular}

a Time of assessment measured since the beginning of observations. Empty cells (...) indicate that no assessment was made at the corresponding date.

b Total number of infected trees.

c Total number of trees. 
symptomatic trees (4). We used the standardization

$$
R\left(\overrightarrow{\mathrm{h}}_{i}\right)=\frac{B B\left(\overrightarrow{\mathrm{h}}_{i}\right)}{E\left[B B\left(\overrightarrow{\mathrm{h}}_{i}\right)\right]}
$$

so that, in the case of spatial randomness, $E\left[R\left(\overrightarrow{\mathrm{h}}_{1}\right)\right]=1$. Values $R\left(\overrightarrow{\mathrm{h}}_{i}\right)>1$ indicate a number of pairs of diseased trees in class $C\left(\overrightarrow{\mathrm{h}}_{i}\right)$ which is greater than expected.

We used simulations to obtain empirical distributions of $R(d)$ (the value of $R(\overrightarrow{\mathrm{h}})$ at fixed $\theta$ ) under the null hypothesis of a random pattern of diseased trees. For each field and each 6-month assessment, 400 sets of simulated data were generated. Each set was obtained by fixing the missing trees and randomly assigning $n_{1}$ infected trees and $\left(n-n_{1}\right)$ healthy trees to the remaining sites. For each direction, the 0.025 and 0.975 quantiles of the 400 simulated curves $R(d)$ determined the 0.95 confidence envelope of $R(d)$ for the null hypothesis. A peak of $R(d)$ was defined as a set of points $(d, R(d))$ with contiguous distance classes $d$ having $R(d)$ significantly $>1$. By reference to core clusters and reflected clusters defined in two-dimensional distance class analysis (14), peaks adjacent to the origin (i.e., including distance $9 \mathrm{~m}$ ) were called core peaks. Other peaks were called reflected peaks. The width of the core peak of each curve, corresponding to the upper distance class $d_{\max }$ in the peak, along with the maximum value $R_{\max }$ of $R(d)$ in the peak, were retained as characteristics of the spatial patterns within clusters, and tabulated. Cumulative cases and new cases were analyzed separately. In the analyses of new cases, trees previously assessed as symptomatic were considered as missing.

Spatiotemporal analysis. Spatiotemporal join count analysis. Spatial measures of autocorrelation for binary data can be extended to spatiotemporal data by considering pairs of points observed at two different times, $t_{1}$ and $t_{2}(4,24,37)$. We defined the spatiotemporal $B B$ join count for spatial lag $\overrightarrow{\mathrm{h}}$ between times $t_{1}$ and $t_{2}$ as the number of pairs of trees comprising a previously diseased tree $\left(t_{1}\right.$ tree) and a newly diseased tree $\left(t_{2}\right.$ tree) separated by spatial lag $\overrightarrow{\mathrm{h}}$. We used the spatiotemporal $B B$ join count to test if $t_{1}$ trees and $t_{2}$ trees separated by spatial lag $\overrightarrow{\mathrm{h}}$ were correlated. Classes of spatial lags were defined in a similar way as for spatial analysis, except that directions $\theta$ and $\theta+180^{\circ}$ were not equivalent because pairs of trees were oriented. Therefore, the angular directions considered were $0^{\circ}, 45^{\circ}, 90^{\circ}, 135^{\circ}, 180^{\circ}, 225^{\circ}$, $270^{\circ}$, and $315^{\circ}$. Omnidirectional classes were also considered. We used the standardization

$$
R\left(\overrightarrow{\mathrm{h}}_{i}\right)=\frac{B B\left(\overrightarrow{\mathrm{h}}_{i}\right)}{E\left[B B\left(\overrightarrow{\mathrm{h}}_{i}\right)\right]}
$$

where $E\left[B B\left(\overrightarrow{\mathrm{h}}_{i}\right)\right]$ is the expected value of $B B\left(\overrightarrow{\mathrm{h}}_{i}\right)$ under the hypothesis of spatial independence between $t_{1}$ trees and $t_{2}$ trees. If $n_{2}$ is the number of $t_{2}$ trees, and $n_{2}^{\prime}$ is the number of asympomatic trees at time $t_{2}$, the total number of $B B$ pairs with the first tree at time $t_{1}$ and the second at time $t_{2}$ is $n_{1} n_{2}$ and the total number of $B W$ such pairs is $n_{1} n_{2}^{\prime}$, so that the probability of drawing at random a $B B$ pair among all $B B$ and $B W$ pairs is $n_{2} /\left(n_{2}+n_{2}^{\prime}\right)$. In case of spatial independence, this probability is the same for all subsets, so that

$$
E\left[B B\left(\overrightarrow{\mathrm{h}}_{i}\right)\right]=A\left(\overrightarrow{\mathrm{h}}_{i}\right) \frac{n_{2}}{n_{2}+n_{2}^{\prime}}
$$

Values $R\left(\overrightarrow{\mathrm{h}}_{i}\right)>1$ indicate a number of $t_{1}-t_{2}$ pairs in class $C\left(\overrightarrow{\mathrm{h}}_{i}\right)$ which is greater than expected. We used simulations to obtain empirical distributions of $R(d)$ in each direction under the assumption of a random pattern of $t_{2}$ trees. For each field and each pair of 6-month assessments, 400 sets of simulated data were generated. Each set was obtained by fixing the $t_{1}$ trees and the missing trees and randomly assigning $n_{2}$ infected trees and $n_{2}^{\prime}$ healthy trees to the remaining sites. Trees assessed as symptomatic before the 6-month assessment $t_{1}$ or between $t_{1}$ and $t_{2}$ were considered to be missing. Core peaks and reflected peaks were defined and analyzed in the same way as for spatial join counts. These peaks correspond to core clusters and reflected clusters, respectively, in spatiotemporal distance class analysis (24).

Semivariogram analysis. The experimental semivariogram is a measure of spatial dependence between values of a quantitative variable $z$ measured at points in the plane separated by a vector, or spatial lag, $\overrightarrow{\mathrm{h}}$. Pairs of points are usually aggregated into classes $C\left(\overrightarrow{\mathrm{h}}_{i}\right)$ so that every pair of points is allocated to the class $C\left(\overrightarrow{\mathrm{h}}_{i}\right)$ defined by the closest spatial lag $\overrightarrow{\mathrm{h}}_{i}$ in distance and orientation. For all lag $\overrightarrow{\mathrm{h}}_{i}$, the experimental semivariogram $\gamma\left(\overrightarrow{\mathrm{h}}_{i}\right)$ is defined as

$$
\gamma\left(\overrightarrow{\mathrm{h}}_{i}\right)=\frac{1}{2 A\left(\overrightarrow{\mathrm{h}}_{i}\right)} \sum_{C\left(\overrightarrow{\mathrm{h}}_{i}\right)}\left[z\left(s_{j}\right)-z\left(s_{k}\right)\right]^{2}
$$

where $z\left(s_{j}\right)$ is the value of the quantitative variable at point $s_{j}$, and the sum is over the class $C\left(\overrightarrow{\mathrm{h}}_{i}\right)$, which contains $A\left(\overrightarrow{\mathrm{h}}_{i}\right)$ pairs (6). We calculated semivariograms of the times of appearance of LY on every symptomatic tree to investigate spatial dependences between these times. Classes $C\left(\overrightarrow{\mathrm{h}}_{i}\right)$ were defined in a similar way as for spatial join counts. Directional semivariograms in directions $0^{\circ}, 45^{\circ}, 90^{\circ}$, and $135^{\circ}$ were plotted and visually compared. Omnidirectional semivariograms were also calculated. We used simulations to obtain empirical distributions of omnidirectional semivariograms under the assumption of random pattern of times of appearance of LY. Two tests were performed, corresponding to two different null hypotheses (27). In the first test, the null hypothesis was complete randomness of times of appearance of LY on the symptomatic trees in the field. Simulated data were obtained by randomly assigning the observed times of appearance of LY to the symptomatic trees. In the second test, the null hypothesis was randomness of times of appearance of LY on the symptomatic trees within clusters. A cluster was defined as a set of spatially related symptomatic trees (i.e., such that two trees in the same cluster could be connected by a path through adjacent trees on the row or between rows). Simulated data were obtained by randomly assigning the observed times of appearance of LY to symptomatic trees within each cluster. In both cases, tests were performed by comparing the observed values of the omnidirectional semivariogram with the distribution of 400 simulated semivariograms.

Statistical analysis. All the analyses were performed using the statistical software package $R$, version 2.8.0 (32). The estimation of the parameters of the $\beta$-binomial distribution by maximum likelihood was performed using the $R$ package aod (18) and the linear regression of the binary power law was performed using the standard $R$ package stats. All the other tests were programmed using $R$. The computation of the spatial and spatiotemporal $B B$ join counts was programmed in $\mathrm{C}$ interfaced with $R$. The source code is available on request to the corresponding author.

\section{RESULTS}

Temporal progress of the disease. During the 34-month assessment period, 6,990 trees were examined in the six fields. The overall cumulative number of infected trees increased from 138 (incidence $=0.0197$ ) at month 1 to 2,418 (incidence $=0.346$ ) at month 34 (Table 2). The progression of LY over time was irregular and peaks of monthly incidence were not the same in every field (Fig. 2). Simple models of disease progress did not fit well the observed data (results not shown). The average values of monthly incidence over the 34-month period were 0.009 (field A), 0.014 (field B), 0.018 (field C), 0.011 (field D), 0.011 (field E), and 0.009 (field F), expressed in new cases of LY per tree per month. Fields A and F, each located at one end of the studied region and separated from the other fields by $>20 \mathrm{~km}$, had lower 
monthly incidence than fields B to $\mathrm{E}$, located in the central region within a maximum distance of $6 \mathrm{~km}$ between $\mathrm{B}$ and $\mathrm{E}$.

Spatial analysis. Distribution of diseased trees per quadrat. Aggregation in disease incidence was detected in every field by the likelihood ratio test. To illustrate, results of square quadrats and of a select group of rectangular quadrats are presented for fields $\mathrm{A}$ and $\mathrm{D}$, which provided contrasting values of $\kappa$ (Table 3 ). Intensity of aggregation differed among fields; except for month 4 , when the incidence of LY was low, in most cases, fields A and $\mathrm{E}$ had the highest values of $\kappa$, fields $\mathrm{D}$ and $\mathrm{F}$ had the lowest values, and fields $B$ and $C$ had intermediate values. In every field, $\kappa$ was greater for small quadrats than for large quadrats and for high incidences than for low incidences. However $\kappa$ did not systematically increase as incidence increased (e.g., in fields A and $\mathrm{D}$, the highest values of $\kappa$ were found for intermediate incidences $[0.240$ to 0.245$]$ ). No relationship between quadrat orientation or shape and the $\beta$-binomial parameter $\kappa$ was detected (results not shown).
For the quadrats $2 \times 2,2 \times 3,3 \times 2,3 \times 3,2 \times 5$, and $5 \times 2$, every distribution of diseased trees obtained from the 36 field assessments (i.e., 6 ratings of 6 fields) was fitted to the $\beta$-binomial distribution. According to a $\chi^{2}$ test of goodness-of-fit at level $5 \%$ (results not shown), the ratios of the number of distributions that could be described adequately by the $\beta$-binomial distribution to the number of $\chi^{2}$ tests that could be performed were $32 / 34(2 \times 2$ quadrat), $31 / 34(2 \times 3), 29 / 34(3 \times 2), 28 / 34(3 \times 3), 34 / 35(2 \times 5)$, and $29 / 33(5 \times 2)$, indicating the adequacy of $\beta$-binomial distribution.

Binary power law. The fit to the binary power law was highly significant for every quadrat type analyzed (Table 4). Estimated slopes were significantly $>1(P<0.001)$, indicating that the degree of heterogeneity varied with incidence and, except for the $2 \times 2$ quadrat, estimated intercepts were significantly $>0$. For all quadrat sizes, most of the points were located above the binomial line (Fig. 3).

Spatial join count analysis. The results of spatial join count analyses for the six fields at the six times of assessment are
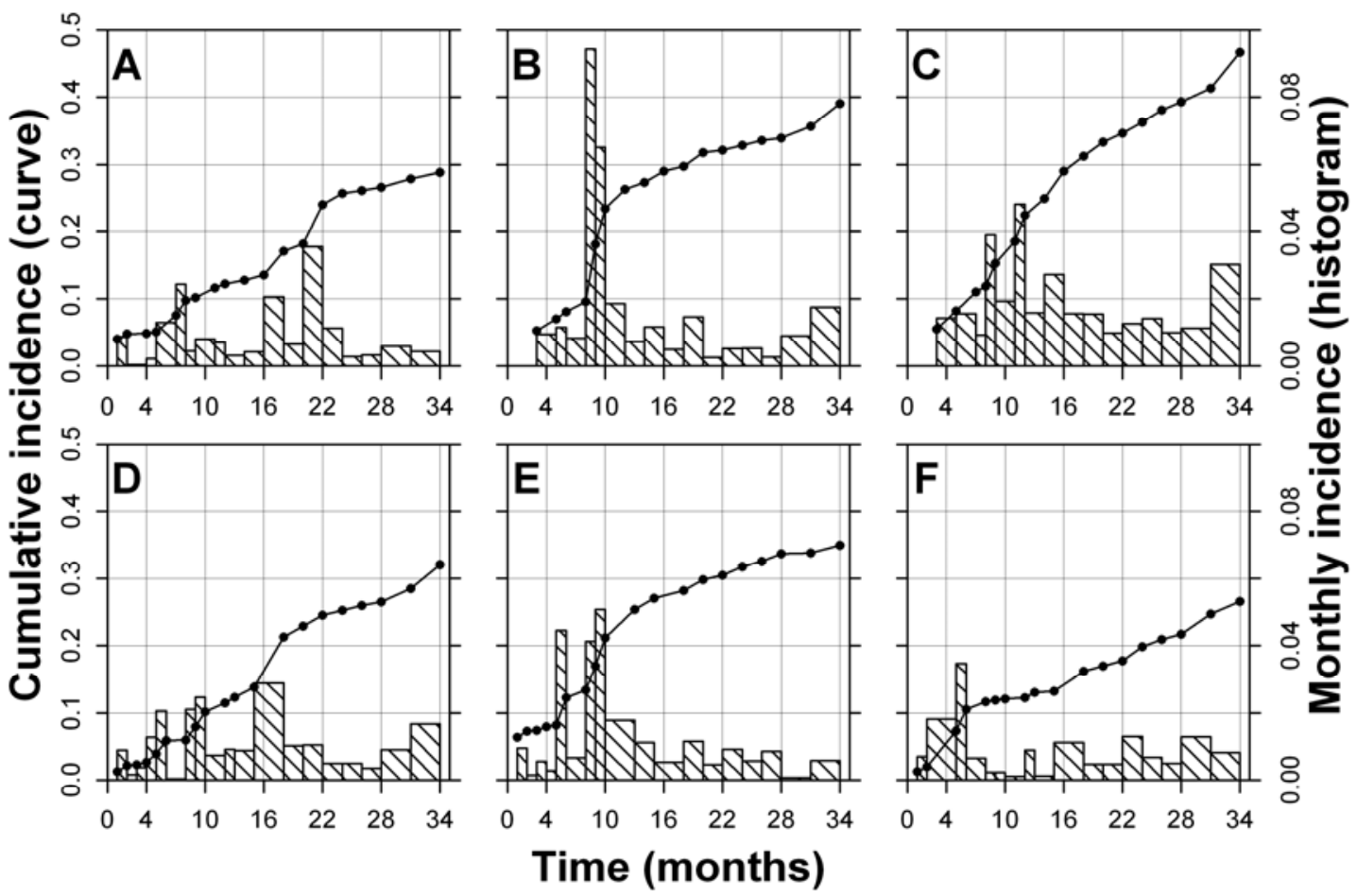

Fig. 2. Cumulative incidence (curve) and monthly incidence (histogram) of coconut lethal yellowing between September 1999 (month 1) and June 2002 (month 34) for the six fields $\mathbf{A}$ to $\mathbf{F}$. Vertical lines correspond to the 6-month assessments retained for spatial and spatiotemporal analyses.

TABLE 3. Aggregation in incidence of coconut lethal yellowing in two selected fields at six dates in Mozambique

\begin{tabular}{|c|c|c|c|c|c|c|c|c|c|c|}
\hline \multirow[b]{2}{*}{ Field, month } & \multirow[b]{2}{*}{ Incidence } & \multicolumn{9}{|c|}{ Coefficient of intraclass correlation $^{\mathrm{a}}$} \\
\hline & & $2 \times 2$ & $2 \times 3$ & $3 \times 2$ & $3 \times 3$ & $2 \times 5$ & $5 \times 2$ & $4 \times 4$ & $5 \times 5$ & $6 \times 6$ \\
\hline \multicolumn{11}{|l|}{ A } \\
\hline 4 & 0.049 & $0.114 * * *$ & $0.097 * * *$ & $0.123 * * *$ & $0.102 * * *$ & $0.082 * * *$ & $0.097 * * *$ & $0.061 * * *$ & $0.066 * * *$ & $0.033 * * *$ \\
\hline 16 & 0.135 & $0.354 * * *$ & $0.342 * * *$ & $0.295^{* * *}$ & $0.312 * * *$ & $0.277 * * *$ & $0.233^{* * *} *$ & $0.244 * * *$ & $0.220 * * *$ & $0.182^{* * *}$ \\
\hline 22 & 0.240 & $0.420 * * *$ & $0.372 * * *$ & $0.375 * * *$ & $0.366 * * *$ & $0.342 * * *$ & $0.323 * * *$ & $0.333 * * *$ & $0.293 * * *$ & $0.247 * * *$ \\
\hline 28 & 0.266 & $0.401 * * *$ & $0.326 * * *$ & $0.355 * * *$ & $0.330 * * *$ & $0.306 * * *$ & $0.312 * * *$ & $0.320 * * *$ & $0.267 * * *$ & 0.218 *** \\
\hline 10 & 0.102 & $0.103 * * *$ & $0.087 * * *$ & $0.103 * * *$ & $0.065 * * *$ & $0.092 * * *$ & $0.064 * * *$ & $0.054 * * *$ & $0.055^{* * *}$ & $0.072 * * *$ \\
\hline 16 & 0.138 & $0.107 * * *$ & $0.058 * *$ & $0.090 * * *$ & $0.048 * *$ & $0.078 * * *$ & $0.064 * * *$ & $0.053 * * *$ & $0.045 * * *$ & $0.057 * * *$ \\
\hline 22 & 0.245 & $0.147 * * *$ & $0.115 * * *$ & $0.113 * * *$ & $0.061 * * *$ & $0.102 * * *$ & $0.095 * * *$ & $0.048 * * *$ & $0.045 * * *$ & $0.067 * * *$ \\
\hline 28 & 0.265 & $0.141 * * *$ & $0.113 * * *$ & $0.106 * * *$ & $0.056 * *$ & $0.109 * * *$ & $0.083 * * *$ & $0.062 * * *$ & $0.045 * * *$ & $0.060 * * *$ \\
\hline 34 & 0.321 & $0.088^{* *}$ & $0.074 * * *$ & $0.079 * * *$ & $0.043^{*}$ & $0.070 * * *$ & $0.053 * *$ & $0.038 * *$ & 0.018 & $0.029 * *$ \\
\hline
\end{tabular}

${ }^{a}$ Maximum likelihood estimate of the coefficient of intraclass correlation $\kappa$ of the $\beta$-binomial distribution. Quadrat size $=$ rows $\times$ trees. Significance of the likelihood ratio test is indicated by $*, * *$, and $* * *$ at levels $P=0.05,0.01$, and 0.001 , respectively. 
summarized in Table 5 for cumulative cases and in Table 6 for new cases. To illustrate, an example of the $R(d)$ curves is shown for cumulative cases in field A at month 10 (Fig. 4). In this case, core peaks were detected in the four directions and for omni-

TABLE 4. Results of the binary power law analysis of the incidence of coconut lethal yellowing in Mozambique

\begin{tabular}{lcccccc}
\hline & \multicolumn{2}{c}{$\ln (A)^{\mathrm{b}}$} & & \multicolumn{2}{c}{$b^{\mathrm{b}}$} & \\
\cline { 2 - 3 } \cline { 5 - 6 } Quadrat $^{\mathrm{a}}$ & Estimate & SE & & Estimate & SE & $R^{2}$ \\
\hline $2 \times 2$ & 0.969 & 0.075 & & 1.140 & 0.021 & 0.964 \\
$2 \times 3$ & 1.388 & 0.121 & & 1.196 & 0.031 & 0.933 \\
$3 \times 2$ & 1.211 & 0.122 & & 1.158 & 0.031 & 0.927 \\
$3 \times 3$ & 1.675 & 0.195 & & 1.199 & 0.045 & 0.866 \\
$2 \times 5$ & 1.893 & 0.159 & & 1.241 & 0.036 & 0.917 \\
$5 \times 2$ & 1.531 & 0.170 & & 1.166 & 0.039 & 0.892 \\
$4 \times 4$ & 2.306 & 0.265 & & 1.260 & 0.055 & 0.831 \\
$5 \times 5$ & 2.827 & 0.346 & & 1.279 & 0.066 & 0.779 \\
$6 \times 6$ & 3.905 & 0.331 & & 1.412 & 0.059 & 0.842 \\
\hline
\end{tabular}

a Quadrat size $=$ rows $\times$ trees

${ }^{\mathrm{b}} \ln (A)$ and $b$ are the coefficients of the line $\ln \left(V_{\text {obs }}\right)=\ln (A)+b \ln \left(V_{\text {bin }}\right)$ estimated by least square regression. $\mathrm{SE}=$ standard error. directional distances with a width $d_{\max }=45$ to $63 \mathrm{~m}$. Beyond this limit, a reflected peak appeared at a distance of $\approx 135 \mathrm{~m}$ in directions $90^{\circ}$ and $135^{\circ}$ and for omnidirectional distances. This spatial pattern suggests isotropy because the four directional curves have a similar aspect within the core peak. For cumulative cases, core peaks were detected in 35 of 36 curves for omnidirectional join counts and in 134 of 144 curves for directional join counts, indicating clustering of symptomatic trees in every field at every 6-month assessment, except for field $\mathrm{F}$ at month 4 (which is the starting month), where incidence was very low (Table 5).

The width $d_{\max }$ of core peaks for omnidirectional and directional curves generally increased with time and, therefore, with incidence for fields $\mathrm{A}, \mathrm{C}$, and $\mathrm{E}$, and remained roughly constant for fields B, D, and F, whereas $R_{\max }$ globally decreased with time for all fields. Fields $\mathrm{A}$ and $\mathrm{E}$ had the widest peaks, fields D and F had the narrowest peaks, and fields B and C had intermediate peak width. The width of the peaks, which can be interpreted as the range of influence of diseased trees on nearby trees, was 9 to $162 \mathrm{~m}$ depending on the time of assessment and the field and, in most cases, was 27 to $108 \mathrm{~m}$. Anisotropy was not
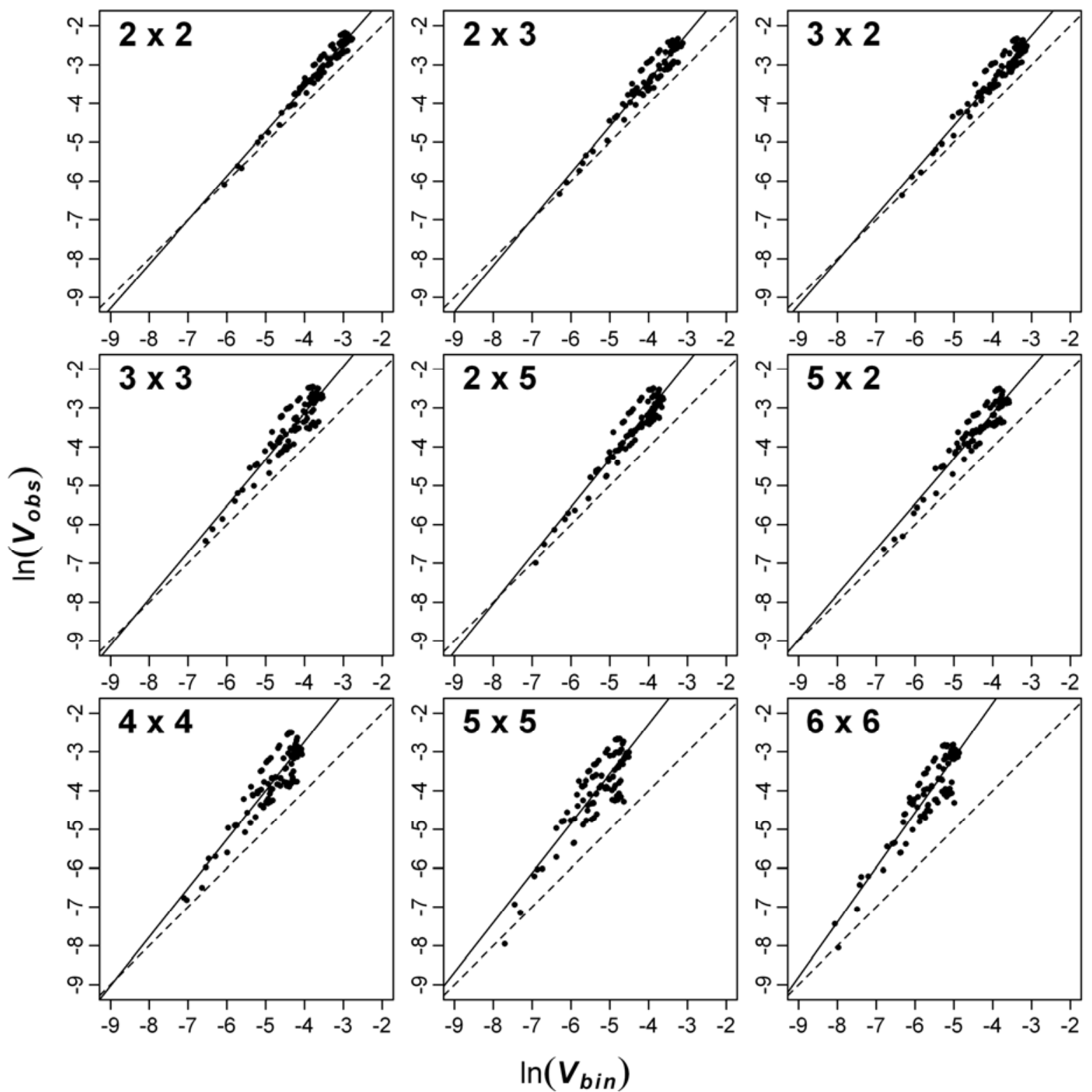

Fig. 3. Relationship between the observed variance $\left(V_{o b s}\right)$ and the theoretical binomial variance $\left(V_{b i n}\right)$ of incidence of coconut lethal yellowing in six fields in Mozambique for nine quadrat sizes. The solid line represents the linear relation between $\ln \left(V_{b i n}\right)$ and $\ln \left(V_{\text {obs }}\right)$ fitted to the data by linear regression. The dashed line represents the binomial line. Each point represents a field assessment at one time of assessment. Quadrat size (rows $\times$ trees) is indicated in each panel. 
formally tested; however, the data in Table 5 suggest that fields D and $\mathrm{F}$ had isotropic patterns, whereas the other fields had widest core peaks in at least one direction: field $\mathrm{A}$ in directions $0^{\circ}$ and $135^{\circ}$, fields $\mathrm{B}$ and $\mathrm{C}$ in direction $90^{\circ}$, and field $\mathrm{E}$ in directions $90^{\circ}$ and $135^{\circ}$ measured clockwise from a perpendicular to the rows. Adding the azimuth of each field (Table 1) to these angles gives the geographical directions of the widest core peaks: $160^{\circ}$ and $295^{\circ}$ for field A, $30^{\circ}$ for fields B and C, and $10^{\circ}$ and $55^{\circ}$ for field E. For fields B, C, and E, the overall direction of the widest core peaks is roughly $30^{\circ}$, which is approximately parallel to the coast.

For new cases, core peaks were detected in omnidirectional curves for at least four of the five assessment periods for every field, indicating clustering of new diseased trees (Table 6). Directional core peaks were also detected but were less frequent than for cumulative cases.

Spatiotemporal analysis. Spatiotemporal join count analysis. Omnidirectional effects were detected in every field but directional effects were detectable only in field A (Table 7). For example, between months 10 and 22 for field A (Fig. 5), core peaks were detected in seven of the eight directions tested with a width $d_{\max }=18$ to $144 \mathrm{~m}$ depending on the direction. A core peak was also detected for omnidirectional distances. The different shapes of the curves in the eight directions suggested anisotropy; however, no formal test was made to confirm it. Anisotropy appeared to occur in other situations (Table 7) for which wide core peaks were detected in particular directions: months 10 to 16 , direction $135^{\circ}, d_{\max }=18$; months 16 to 22 , direction $45^{\circ}$, $d_{\max }=10$; and months 10 to 22 , directions $0^{\circ}$ and $315^{\circ}, d_{\max }=16$. However, such anisotropy was not a constant characteristic of the area because it never occurred in the same direction, and may have been purely random. Core peak widths were always $\leq 162 \mathrm{~m}$. Core peaks had their maximum value at 9 to $18 \mathrm{~m}$, indicating that these distances were the most frequent between a previously diseased tree and a newly diseased tree.

For omnidirectional join counts, core peaks were detected in every field (Table 8), indicating that new cases appeared more frequently next to previously diseased trees. The ratios of significant core peaks to all core peaks tested for temporal lags 6,12 , 18, 24, and 30 months calculated from Table 8 were 16/30, 12/24, $5 / 18,1 / 12$, and $0 / 6$, respectively. These decreasing values indicated that trees became diseased preferentially 6 or 12 months after their neighbors, although periods of 18 months or more were possible. These values were only approximations because data were grouped by periods of 6 months.

Semivariogram analysis. For every field, semivariograms of the time of appearance of LY in directions $0^{\circ}, 45^{\circ}, 90^{\circ}$, and $135^{\circ}$

TABLE 5. Summary of spatial join count analysis of cumulative cases of coconut lethal yellowing in six fields at six times of assessment in Mozambique

\begin{tabular}{|c|c|c|c|c|c|c|c|c|c|c|}
\hline \multirow[b]{3}{*}{ Field, month } & \multicolumn{10}{|c|}{ Orientation $^{\mathrm{a}}$} \\
\hline & \multicolumn{2}{|c|}{ Omnidirectional } & \multicolumn{2}{|c|}{$0^{\circ}$} & \multicolumn{2}{|c|}{$45^{\circ}$} & \multicolumn{2}{|c|}{$90^{\circ}$} & \multicolumn{2}{|c|}{$135^{\circ}$} \\
\hline & Width & $\operatorname{Rmax}$ & Width & Rmax & Width & Rmax & Width & Rmax & Width & $\operatorname{Rmax}$ \\
\hline \multicolumn{11}{|l|}{ A } \\
\hline 4 & 54 & 3.77 & 63 & 3.84 & 27 & 3.75 & 27 & 4.00 & 45 & 4.02 \\
\hline 10 & 63 & 4.30 & 63 & 4.29 & 63 & 4.37 & 45 & 4.61 & 63 & 3.90 \\
\hline 16 & 81 & 3.36 & 81 & 3.52 & 72 & 3.23 & 63 & 3.34 & 144 & 3.35 \\
\hline 22 & 126 & 2.30 & 162 & 2.30 & 72 & 2.20 & 81 & 2.34 & 162 & 2.36 \\
\hline 28 & 108 & 2.08 & 162 & 2.11 & 72 & 2.00 & 81 & 2.14 & 162 & 2.12 \\
\hline 34 & 108 & 1.92 & 162 & 1.97 & 72 & 1.87 & 81 & 2.00 & 144 & 1.95 \\
\hline \multicolumn{11}{|l|}{ B } \\
\hline 4 & 54 & 5.09 & 36 & 5.33 & 45 & 5.06 & 72 & 5.57 & 45 & 5.26 \\
\hline 10 & 54 & 1.82 & 36 & 1.97 & 45 & 1.71 & 108 & 1.89 & 54 & 1.73 \\
\hline 16 & 54 & 1.60 & 45 & 1.65 & 45 & 1.55 & 126 & 1.63 & 54 & 1.57 \\
\hline 22 & 54 & 1.56 & 36 & 1.60 & 45 & 1.44 & 108 & 1.64 & 54 & 1.56 \\
\hline 28 & 54 & 1.48 & 36 & 1.54 & 45 & 1.45 & 108 & 1.58 & 54 & 1.43 \\
\hline 34 & 45 & 1.33 & 36 & 1.37 & 45 & 1.32 & 108 & 1.38 & 36 & 1.32 \\
\hline \multicolumn{11}{|l|}{$\mathrm{C}$} \\
\hline 4 & 36 & 4.89 & 9 & 4.45 & 18 & 5.24 & 63 & 5.64 & 18 & 4.16 \\
\hline 10 & 54 & 2.26 & 27 & 2.61 & 36 & 2.18 & 144 & 2.35 & 36 & 1.89 \\
\hline 16 & 63 & 1.55 & 36 & 1.59 & 63 & 1.55 & 126 & 1.59 & 36 & 1.45 \\
\hline 22 & 63 & 1.40 & 36 & 1.43 & 63 & 1.40 & 144 & 1.48 & 45 & 1.33 \\
\hline 28 & 63 & 1.29 & 36 & 1.29 & 63 & 1.29 & 144 & 1.38 & 45 & 1.23 \\
\hline 34 & 63 & 1.21 & 36 & 1.22 & 63 & 1.21 & 180 & 1.32 & 45 & 1.20 \\
\hline \multicolumn{11}{|l|}{$\mathrm{D}$} \\
\hline 4 & 36 & 4.39 & 9 & 5.07 & $\ldots$ & $\ldots$ & 9 & 6.02 & $\ldots$ & $\ldots$ \\
\hline 10 & 45 & 1.73 & 9 & 1.66 & $\ldots$ & $\ldots$ & 27 & 2.69 & $\ldots$ & $\ldots$ \\
\hline 16 & 9 & 1.55 & 9 & 1.57 & $\ldots$ & $\ldots$ & 9 & 2.01 & $\begin{array}{l}\cdots \\
\ldots\end{array}$ & $\begin{array}{l}\cdots \\
\ldots\end{array}$ \\
\hline 22 & 36 & 1.40 & 9 & 1.44 & 9 & 1.33 & 18 & 1.60 & 27 & 1.20 \\
\hline 28 & 36 & 1.36 & 9 & 1.39 & 9 & 1.29 & 27 & 1.54 & 18 & 1.22 \\
\hline 34 & 36 & 1.22 & 9 & 1.21 & 9 & 1.16 & 18 & 1.36 & 9 & 1.16 \\
\hline \multicolumn{11}{|l|}{ E } \\
\hline 4 & 63 & 3.45 & 27 & 3.21 & 36 & 3.76 & 180 & 4.04 & 36 & 2.82 \\
\hline 10 & 36 & 2.00 & 27 & 1.98 & 27 & 1.94 & 54 & 2.20 & 36 & 1.93 \\
\hline 16 & 54 & 1.69 & 36 & 1.59 & 27 & 1.63 & 54 & 1.88 & 63 & 1.63 \\
\hline 22 & 162 & 1.49 & 36 & 1.46 & 45 & 1.45 & 90 & 1.59 & 63 & 1.48 \\
\hline 28 & 162 & 1.50 & 63 & 1.52 & 72 & 1.49 & 144 & 1.52 & 180 & 1.50 \\
\hline 34 & 162 & 1.50 & 72 & 1.50 & 72 & 1.47 & 144 & 1.51 & 162 & 1.54 \\
\hline \multicolumn{11}{|l|}{$\mathrm{F}$} \\
\hline 4 & $\ldots$ & $\ldots$ & $\ldots$ & $\ldots$ & $\ldots$ & $\ldots$ & $\ldots$ & $\ldots$ & $\ldots$ & $\ldots$ \\
\hline 10 & 27 & 2.10 & 9 & 1.91 & 18 & 2.07 & 18 & 2.18 & 9 & 2.25 \\
\hline 16 & 27 & 2.17 & 18 & 1.93 & 18 & 2.06 & 18 & 2.19 & 18 & 2.49 \\
\hline 22 & 18 & 1.69 & 9 & 1.65 & 9 & 1.49 & 9 & 1.74 & 9 & 1.85 \\
\hline 28 & 27 & 1.60 & 9 & 1.61 & 9 & 1.53 & 9 & 1.60 & 9 & 1.64 \\
\hline 34 & 45 & 1.48 & 9 & 1.48 & 9 & 1.41 & 18 & 1.49 & 27 & 1.56 \\
\hline
\end{tabular}

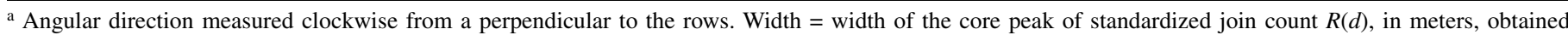
from the 0.95 confidence envelope. Rmax = maximum value of $R(d)$ over the core peak. Empty cells (...) represent curves without significant core peak. 
increased between 9 and 54 to $90 \mathrm{~m}$ (Fig. 6). Beyond $90 \mathrm{~m}$, divergence between directional semivariograms sometimes occurred but was not systematic. In the following, only omnidirectional semivariograms are considered.

For every field, there was a regular increase in the semivariogram between 9 and 54 to $90 \mathrm{~m}$ (Fig. 7), and the value of the semivariogram at $9 \mathrm{~m}$ was always significantly lower than expected in the case of complete spatial independence. This result indicated a tendency for neighboring trees to become diseased at shorter time lags than average, and that these lags increased with the distance between trees. In the first test, the critical distance, determined by the point at which the value of the semivariogram reached the 0.95 lower confidence limit of simulated data, ranged from $\approx 18 \mathrm{~m}$ for fields $\mathrm{D}$ and $\mathrm{E}$ to $180 \mathrm{~m}$ for field $\mathrm{B}$. However, in the latter case, the semivariogram was very close to the confidence limit at $63 \mathrm{~m}$, so that its lower values beyond this distance could be an artifact caused by interference between clusters. For the other fields, the critical distance did not exceed $63 \mathrm{~m}$. The second test, although statistically less powerful, rejected spatial randomness of time of appearance of LY within clusters in every field except for field E (Fig. 7). The critical distance varied from $\approx 9 \mathrm{~m}$ for fields $\mathrm{D}$ and $\mathrm{F}$ to $36 \mathrm{~m}$ for fields $\mathrm{A}$ and $\mathrm{C}$. This indicated that the tendency for neighboring trees to become diseased at shorter than average time lags was not due only to variability between clusters and that, therefore, there was a spatial structure of time of appearance of LY within clusters. This strongly suggests a secondary spread within clusters.

\section{DISCUSSION}

The incidence of coconut LY in Mozambique was found to be aggregated in space and time within fields of 700 to 1,500 trees. Over a period of 34 months, the disease status of any single tree was dependent on the disease status of trees at distances of up to $180 \mathrm{~m}$ and was influenced by the status of these trees 6 to 12 months earlier.

Temporal progress of the disease. Simple models of disease progress did not fit well to the observed data. This result is in disagreement with other studies, where the logistic model could be fitted to incidence of LY-type diseases. The logistic model was used by McCoy for LY in Florida and in Jamaica, for Kaincope disease in Togo, and for cadang-cadang in the Philippines (20); by Schuiling et al. for LY in Tanzania (35); and by Steiner for Kaincope disease in Togo (36). Some of these studies, however, concerned much larger areas than the six fields we observed in Mozambique, because the number of trees assessed could reach 350,000 (20). This difference in sample size could explain the more erratic shape of our observed curves.

Spatial analyses. LY incidence was investigated for aggregation on cumulative cases of LY symptomatic trees and on new cases. Analyses of the distribution of diseased trees per quadrat and analyses of spatial join counts were in agreement in quantifying the intensity of aggregation, because the width of the omnidirectional core peak was correlated with the coefficient $\kappa$ of spatial autocorrelation at fixed quadrat size. For $5 \times 5$ quadrats, the

TABLE 6. Summary of spatial join count analysis of new cases of coconut lethal yellowing in six fields at six dates in Mozambique

\begin{tabular}{|c|c|c|c|c|c|c|c|c|c|c|}
\hline \multirow[b]{3}{*}{ Field, month } & \multicolumn{10}{|c|}{ Orientation $^{\mathrm{a}}$} \\
\hline & \multicolumn{2}{|c|}{ Omnidirectional } & \multicolumn{2}{|c|}{$0^{\circ}$} & \multicolumn{2}{|c|}{$45^{\circ}$} & \multicolumn{2}{|c|}{$90^{\circ}$} & \multicolumn{2}{|c|}{$135^{\circ}$} \\
\hline & Width & $\mathrm{Rmax}$ & Width & $\operatorname{Rmax}$ & Width & $R \max$ & Width & $\mathrm{R} \max$ & Width & Rmax \\
\hline 10 & 63 & 6.27 & 63 & 6.33 & 72 & 6.44 & 54 & 6.93 & 54 & 5.35 \\
\hline 16 & 108 & 4.24 & 9 & 5.65 & 18 & 4.47 & 27 & 5.05 & $\ldots$ & \\
\hline 22 & 81 & 2.77 & 63 & 2.69 & 72 & 2.75 & 81 & 2.99 & 45 & 2.66 \\
\hline 28 & 18 & 2.53 & $\ldots$ & $\ldots$ & $\ldots$ & $\ldots$ & 18 & 5.65 & $\ldots$ & $\ldots$ \\
\hline 10 & 36 & 1.55 & 27 & 1.96 & $\ldots$ & $\ldots$ & 54 & 1.45 & 36 & 1.51 \\
\hline 16 & $\ldots$ & $\ldots$ & $\ldots$ & $\ldots$ & $\ldots$ & $\ldots$ & $\ldots$ & $\ldots$ & $\ldots$ & $\ldots$ \\
\hline 22 & 9 & 2.57 & 9 & 5.05 & $\ldots$ & $\ldots$ & $\ldots$ & $\ldots$ & $\ldots$ & $\ldots$ \\
\hline 28 & 9 & 6.33 & $\ldots$ & $\ldots$ & $\ldots$ & $\ldots$ & 9 & 12.01 & $\ldots$ & $\ldots$ \\
\hline 34 & 27 & 2.26 & 9 & 3.88 & $\ldots$ & $\ldots$ & $\ldots$ & $\ldots$ & $\ldots$ & $\ldots$ \\
\hline \multicolumn{11}{|l|}{$\mathrm{C}$} \\
\hline 10 & 54 & 2.18 & 9 & 3.05 & 45 & 2.15 & 144 & 2.17 & $\ldots$ & $\ldots$ \\
\hline 10 & 27 & 1.58 & $\ldots$ & $\ldots$ & $\ldots$ & $\ldots$ & 27 & 3.02 & $\ldots$ & $\ldots$ \\
\hline 16 & $\ldots$ & $\ldots$ & $\ldots$ & $\ldots$ & $\ldots$ & $\ldots$ & $\ldots$ & $\ldots$ & $\ldots$ & $\ldots$ \\
\hline 22 & 9 & 1.39 & $\ldots$ & $\ldots$ & $\ldots$ & $\ldots$ & $\ldots$ & $\ldots$ & $\ldots$ & $\ldots$ \\
\hline 28 & 9 & 5.42 & $\ldots$ & $\ldots$ & $\ldots$ & $\ldots$ & 18 & 14.25 & $\ldots$ & $\ldots$ \\
\hline 34 & 36 & 1.67 & $\ldots$ & $\ldots$ & $\ldots$ & $\ldots$ & 18 & 2.73 & $\ldots$ & $\ldots$ \\
\hline \multicolumn{11}{|l|}{ E } \\
\hline 10 & 27 & 2.34 & 9 & 2.23 & 18 & 2.27 & 27 & 2.73 & 36 & 2.09 \\
\hline 16 & 27 & 2.62 & $\ldots$ & $\ldots$ & $\ldots$ & $\ldots$ & 18 & 3.16 & 9 & 3.76 \\
\hline 22 & 9 & 2.57 & $\ldots$ & $\ldots$ & $\ldots$ & $\ldots$ & - & - & $\ldots$ & $\ldots$ \\
\hline 28 & $\ldots$ & $\ldots$ & $\ldots$ & $\ldots$ & $\ldots$ & $\ldots$ & 18 & 6.59 & $\ldots$ & $\ldots$ \\
\hline 34 & 9 & 10.79 & $\ldots$ & $\ldots$ & $\ldots$ & $\ldots$ & 9 & 16.12 & $\ldots$ & $\ldots$ \\
\hline \multicolumn{11}{|l|}{$\mathrm{F}$} \\
\hline 10 & 18 & 2.19 & 9 & 1.77 & 27 & 2.23 & 18 & 2.47 & 18 & 2.25 \\
\hline
\end{tabular}

a Angular direction measured clockwise from a perpendicular to the rows. Width $=$ width of the core peak of standardized join count $R(d)$, in meters, obtained from the 0.95 confidence envelope. Rmax = maximum value of $R(d)$ over the core peak. Empty cells $(\ldots)$ represent curves without significant core peak. 
coefficient of linear correlation between these two parameters calculated with the 36 available pairs of values was 0.75 . This positive correlation can be explained by observing that, when the size of aggregates increases, the width of the core peak increases along with the number of quadrats covered by the aggregates, which contributes to an increase in $\kappa$ because the quadrats contain trees with a disease status that is more similar than by random chance. Although anisotropy was not formally tested, it was suggested by results of join count analyses for four of six fields, and corresponded roughly to the same geographic direction for three of them. However, because this direction also corresponded to the orientation of the rows, this anisotropy could have been caused by an unknown factor linked to rows. For new cases, the spatial patterns were not analyzed with the quadrat method because many quadrats would have been empty or very incomplete. Join count analysis detected an omnidirectional core peak in most situations, indicating that new diseased trees appeared in clusters. Directional core peaks were more difficult to detect than for cumulative cases because the number of oriented pairs of new cases was lower.
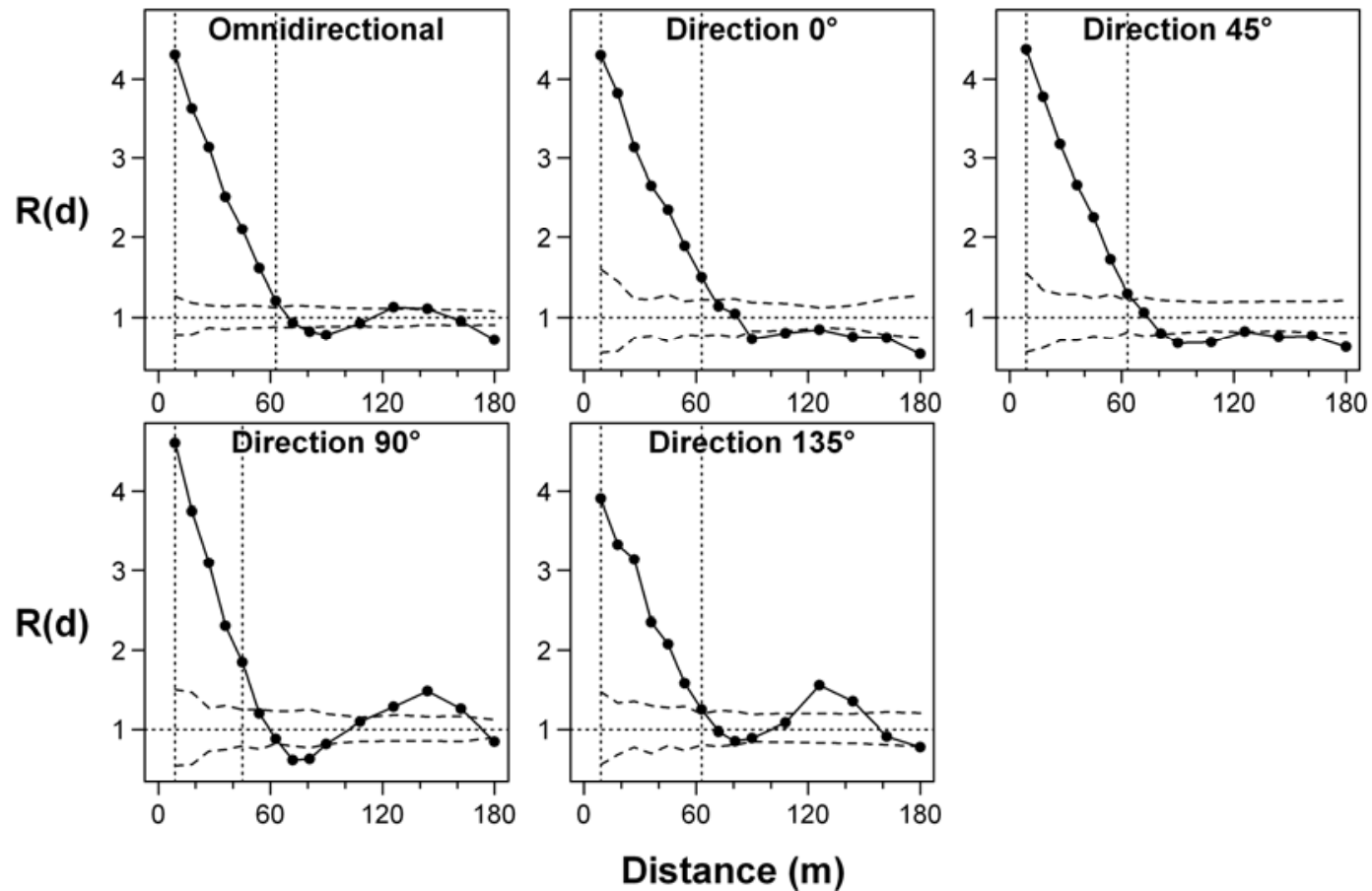

Fig. 4. Omnidirectional and directional spatial dependence between cumulative cases of coconut lethal yellowing in field A at month 10 . The curves represent the standardized join count $R(d)$ of symptomatic trees against distance. Dashed lines indicate the 0.95 confidence envelope obtained from 400 simulations under the hypothesis of spatial independence. Vertical dotted lines indicate the core peak.

TABLE 7. Summary of spatiotemporal directional and omnidirectional join count analysis of new cases of coconut lethal yellowing in field A at five time lags corresponding to 15 pairs of $t_{1}-t_{2}$ months

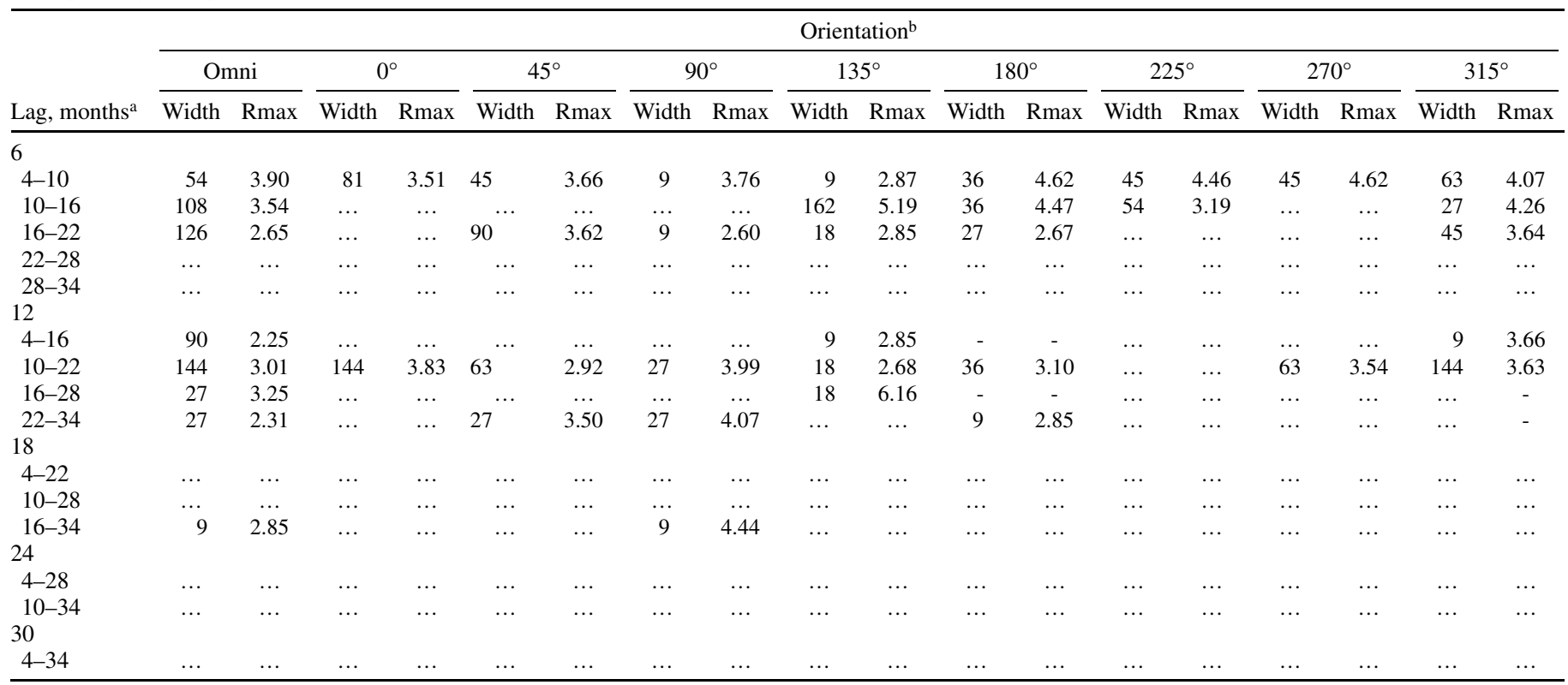

${ }^{a}$ Lag in months between assessment times $t_{1}$ and $t_{2}$; months $=t_{1}$ and $t_{2}$ assessment times.

b Angular direction measured clockwise from a perpendicular to the rows. Omni = omnidirectional. Width $=$ width of the core peak of standardized join count $R(d)$, in meters, obtained from the 0.95 confidence envelope. Rmax = maximum value of $R(d)$ over the core peak. Empty cells (...) represent curves without significant core peak. 
Spatiotemporal analyses. Spatiotemporal join count analysis and analysis of the semivariogram of time of appearance of LY were used to characterize how the time lag between appearance of LY was related to the distance between symptomatic trees. The two methods were in agreement in quantifying the relations in space and time between symptomatic trees. This result is not surprising because the hypotheses tested are related: spatiotemporal join count analysis tests the randomness of distances between two sets of trees, given the time lag between the disease appearance in the two sets; and the analysis of the semivariogram tests the randomness of time lags of disease appearance in pairs of trees, given the distance between trees. Analysis of the semivariogram of time of appearance of LY provides the complementary information that the average time lag increases with the distance between symptomatic trees, within the limit of the range of the semivariogram that is $\approx 60 \mathrm{~m}$. The isotropy of semivariograms at short distances is compatible with possible aniso- tropy of curves of $R$ values of spatiotemporal join counts. This apparent contradiction can be explained by the hypothesis that anisotropic patterns for pairs of specific 6-month assessments are random and become undetectable when all the times of appearance of LY are combined in a single semivariogram.

Epidemiological interpretation. Spatial and spatiotemporal patterns of LY were found to have the same general properties in all six fields. Clustering of LY-infected trees was detected for cumulative cases as well as for new cases grouped by assessment periods of 6 months. Furthermore, the new cases had a tendency to appear closer to previously diseased trees than would occur by random chance. The average difference between times of appearance of LY increased as distance increased from $9 \mathrm{~m}$ to $\approx 60 \mathrm{~m}$. These statistical properties did not exclude new isolated cases, which could remain isolated (or not) as incidence increased. These results are in agreement with those of previous studies, which reported spatial autocorrelation of LY-infected trees
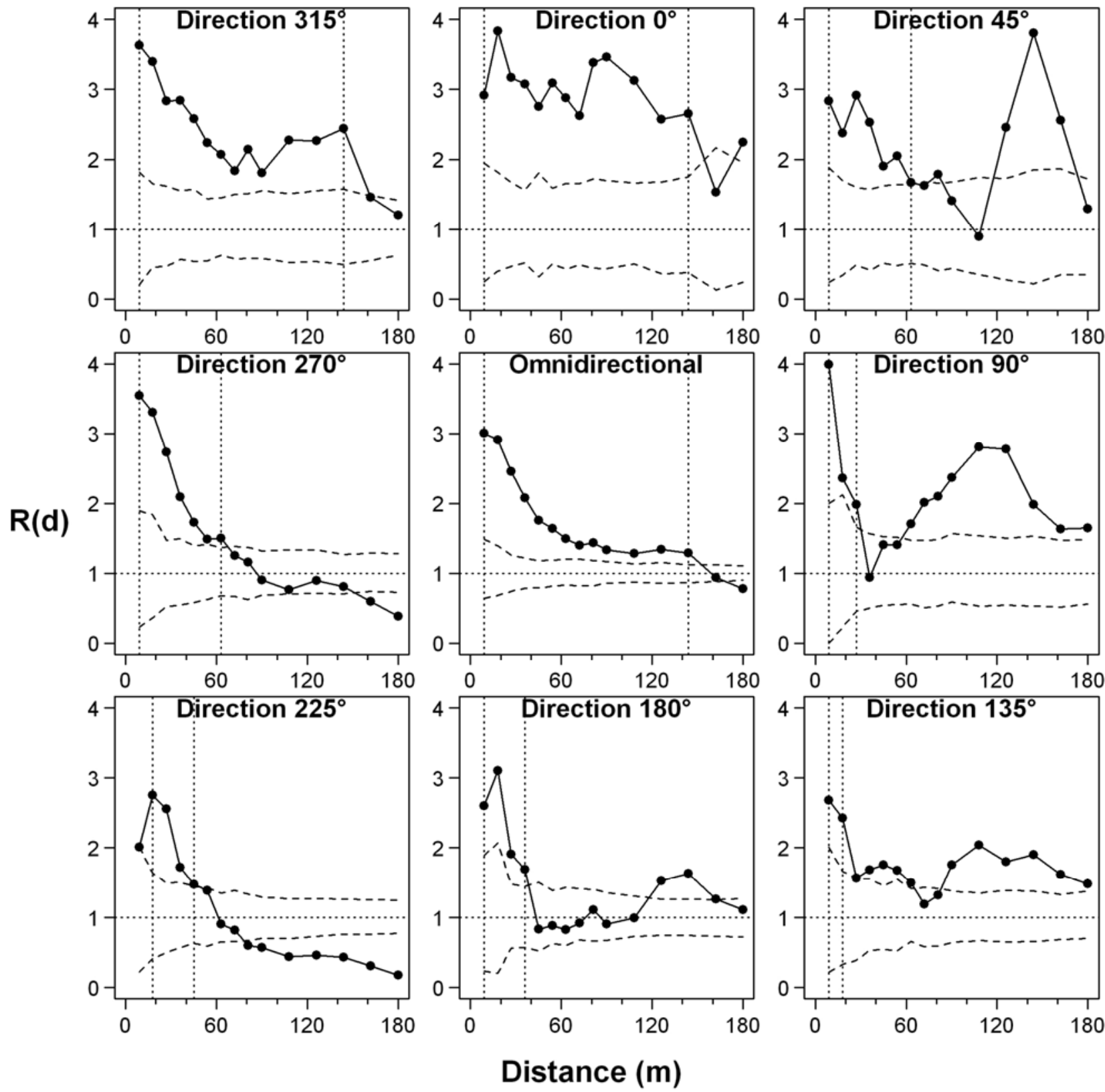

Fig. 5. Omnidirectional (center) and directional spatiotemporal dependence between cases of coconut lethal yellowing observed at two 6-month assessments in field A. First assessment: month 10. Second assessment: month 22. Symptomatic trees observed at months 11 to 16 were considered as missing. The curves represent the standardized join count $R(d)$ between $t_{1}$ and $t_{2}$ trees against distance. Dashed lines indicate the 0.95 confidence envelope obtained from 400 simulations. Vertical dotted lines indicate the first peak. All peaks except in direction $225^{\circ}$ are core peaks. 


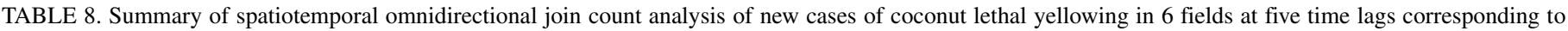
15 pairs of $t_{1}-t_{2}$ months ${ }^{\mathrm{a}}$

\begin{tabular}{|c|c|c|c|c|c|c|c|c|c|c|c|c|}
\hline \multirow[b]{2}{*}{ Lag, months ${ }^{\mathrm{b}}$} & \multicolumn{2}{|c|}{ Field A } & \multicolumn{2}{|c|}{ Field B } & \multicolumn{2}{|c|}{ Field C } & \multicolumn{2}{|c|}{ Field D } & \multicolumn{2}{|c|}{ Field E } & \multicolumn{2}{|c|}{ Field F } \\
\hline & Width & Rmax & Width & $R \max$ & Width & Rmax & Width & $\operatorname{Rmax}$ & Width & $\mathrm{Rmax}$ & Width & $R \max$ \\
\hline \multicolumn{13}{|l|}{6} \\
\hline $4-10$ & 54 & 3.90 & 63 & 2.13 & 45 & 1.93 & 9 & 1.54 & 36 & 1.55 & 9 & 2.02 \\
\hline $10-16$ & 108 & 3.54 & 9 & 1.41 & 9 & 1.39 & $\ldots$ & $\ldots$ & 18 & 1.68 & 18 & 3.12 \\
\hline $16-22$ & 126 & 2.65 & $\ldots$ & $\ldots$ & $\ldots$ & $\ldots$ & 9 & 1.39 & $\ldots$ & $\ldots$ & $\ldots$ & $\ldots$ \\
\hline $22-28$ & $\ldots$ & $\ldots$ & $\ldots$ & $\ldots$ & $\ldots$ & $\ldots$ & $\ldots$ & $\ldots$ & 9 & 2.59 & $\ldots$ & $\ldots$ \\
\hline $28-34$ & $\ldots$ & $\ldots$ & $\ldots$ & $\ldots$ & $\ldots$ & $\ldots$ & $\ldots$ & $\ldots$ & 9 & 3.71 & $\ddot{90}$ & 2.34 \\
\hline \multicolumn{13}{|l|}{12} \\
\hline 4-16 & 90 & 2.25 & 36 & 1.93 & 36 & 1.68 & 9 & 2.37 & $\ldots$ & $\ldots$ & $\ldots$ & $\ldots$ \\
\hline $10-22$ & 144 & 3.01 & 9 & 1.55 & $\ldots$ & $\ldots$ & 18 & 1.43 & $\ldots$ & $\ldots$ & $\ldots$ & $\ldots$ \\
\hline $16-28$ & 27 & 3.25 & $\ldots$ & $\ldots$ & $\ldots$ & $\ldots$ & $\ldots$ & $\ldots$ & $\ldots$ & $\ldots$ & 63 & 3.06 \\
\hline $22-34$ & 27 & 2.31 & $\ldots$ & $\ldots$ & 63 & 1.72 & $\ldots$ & $\ldots$ & 36 & 4.54 & $\ldots$ & $\ldots$ \\
\hline \multicolumn{13}{|l|}{18} \\
\hline $4-22$ & $\ldots$ & $\ldots$ & 9 & 2.26 & $\ldots$ & $\ldots$ & 9 & 1.55 & $\ldots$ & $\ldots$ & $\ldots$ & $\ldots$ \\
\hline $10-28$ & $\ldots$ & $\ldots$ & $\ldots$ & $\ldots$ & $\ldots$ & $\ldots$ & 18 & 1.95 & 9 & 1.85 & $\ldots$ & $\ldots$ \\
\hline $16-34$ & 9 & 2.85 & $\ldots$ & $\ldots$ & $\ldots$ & $\ldots$ & $\ldots$ & $\ldots$ & $\ldots$ & $\ldots$ & $\ldots$ & $\ldots$ \\
\hline \multicolumn{13}{|l|}{24} \\
\hline $4-28$ & $\ldots$ & $\ldots$ & $\ldots$ & $\ldots$ & $\ldots$ & $\ldots$ & $\ldots$ & $\ldots$ & 81 & 2.72 & $\ldots$ & $\ldots$ \\
\hline $10-34$ & $\ldots$ & $\ldots$ & $\ldots$ & $\ldots$ & $\ldots$ & $\ldots$ & $\ldots$ & $\ldots$ & $\ldots$ & $\ldots$ & $\ldots$ & $\ldots$ \\
\hline \multicolumn{13}{|l|}{30} \\
\hline 4-34 & $\ldots$ & $\ldots$ & $\ldots$ & $\ldots$ & $\ldots$ & $\ldots$ & $\ldots$ & $\ldots$ & $\ldots$ & $\ldots$ & $\ldots$ & $\ldots$ \\
\hline
\end{tabular}

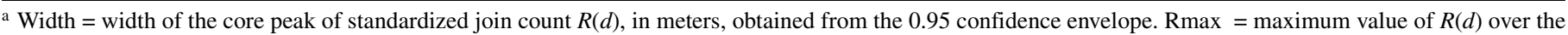
core peak. Empty cells (...) represent curves without significant core peak.

${ }^{\mathrm{b}}$ Lag in months between assessment times $t_{1}$ and $t_{2}$. Months $=t_{1}$ and $t_{2}$ assessment times.

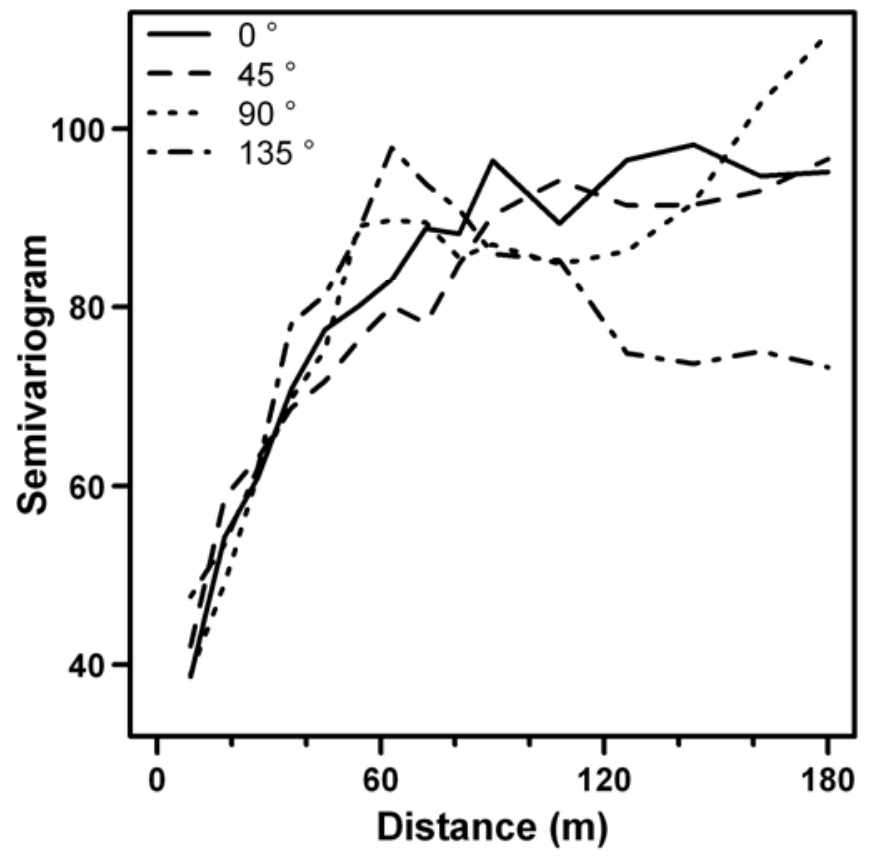

Fig. 6. Directional semivariograms of times of appearance of coconut lethal yellowing in field A.

(11,13). According to McCoy (20), most spread of LY occurs within a local area, possibly $100 \mathrm{~m}$ in diameter surrounding an active focus of disease, but diseased trees may appear several to $>100 \mathrm{~km}$ apart from previously infected trees, thereby establishing new disease foci.

We must consider heterogeneity in disease incidence within fields and among fields. It is unlikely that heterogeneity within fields was caused by differences in genetic material or age because, in commercial plantations, each field is planted within 1 or 2 weeks with homogeneous material. Contamination of trees before planting can be excluded because contamination of embryo or seedling by LY was never reported. Heterogeneity caused by plantation operations is unlikely because mechanical inoculation is not possible. Therefore, clustered new cases prob- ably occurred because the disease was transmitted by the vector to neighboring trees. At least two mechanisms could lead to the patterns observed. The first is simultaneous infection of neighboring trees by the same insect, possibly coming from a remote infected tree. Indeed, it is known that diseases caused by phytoplasmas are frequently transmitted in persistent mode (31), so that an infected insect remains infectious throughout its life and can inoculate several trees. In this case, the increasing difference between times of appearance of LY with distance would result from heterogeneity between clusters, each originating from the arrival of insects at possibly different times, contrasting with the homogeneity of neighboring trees inoculated at nearly the same time within each cluster. The second mechanism is secondary spread of the disease from infected trees to their neighboring trees, in which case the increasing difference between times of appearance of LY with distance would merely reflect the progress of the disease in space and over time. A strong argument in favor of this secondary spread at short distance is the within-cluster spatial structure of times of appearance of LY, which suggests a spatial gradient of time well explained by the propagation of the disease from a tree to its neighbors. In the case of simultaneous infection of neighboring trees, a random distribution of times of appearance of LY within clusters would rather be expected. It is worth noting that only the test based on local permutations of times of appearance of LY within clusters is able to detect the secondary spread, while the test based on complete permutations mixes the two possible mechanisms.

Differences among fields in disease incidence and aggregation can probably be influenced by several factors. Fields B and C, for example, which were homogeneous in that they were separated by only $500 \mathrm{~m}$ and were planted in the same year, had the highest incidence (Fig. 2), similar values of $\kappa$, and similar widths of the core peaks of cumulative cases of LY (Table 5). However, it was not possible to establish a relation between aggregation in disease incidence and location or age of the fields.

The time after which new cases were found to appear significantly in the immediate proximity of previously diseased trees can provide information about the incubation period of the disease. If there is secondary spread of the disease, it is likely that newly diseased trees were contaminated preferentially, although not exclusively, by their neighbors. This time was found to be $\approx 6$ 

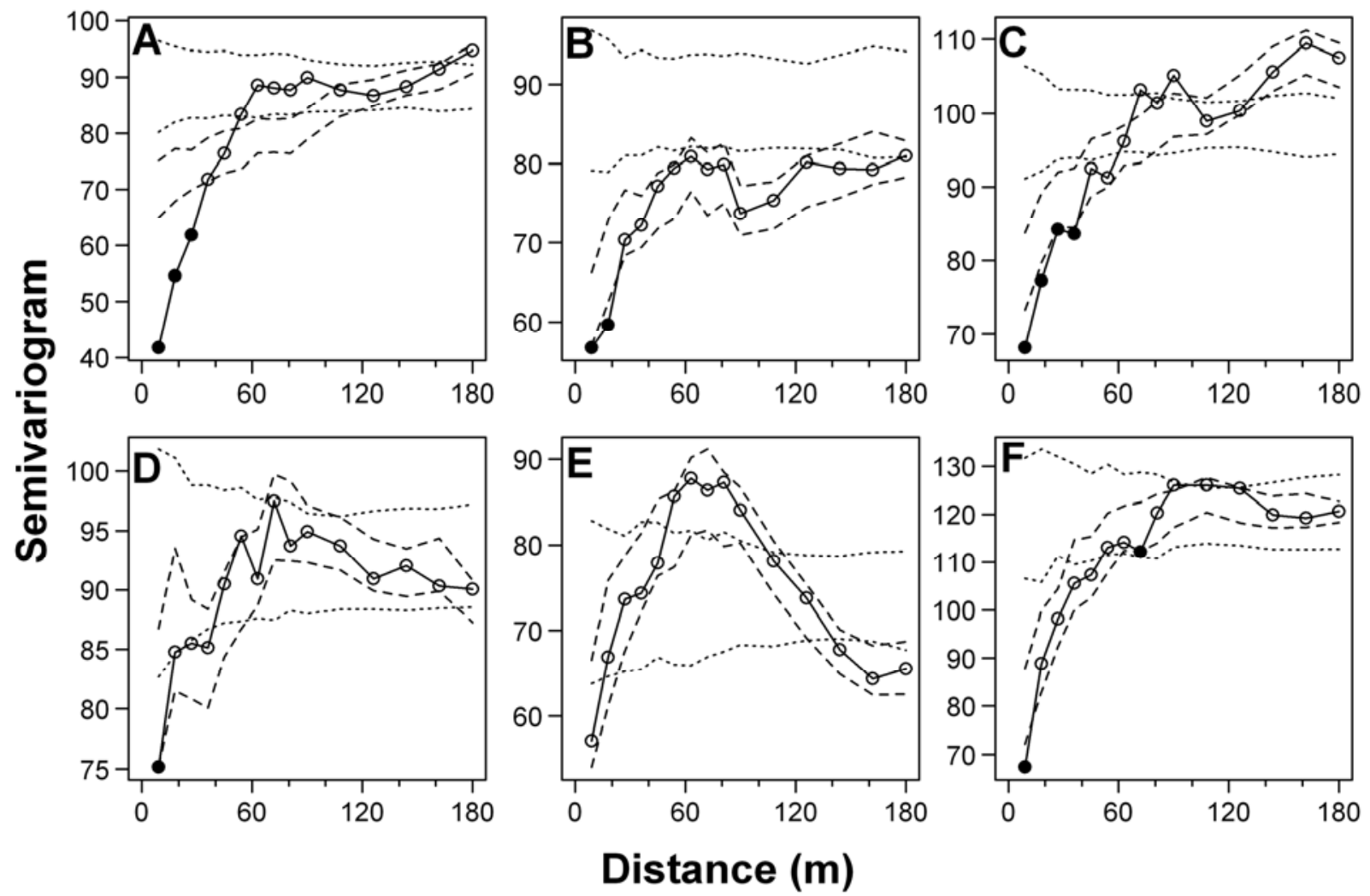

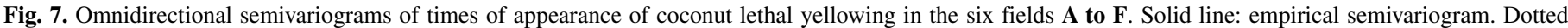

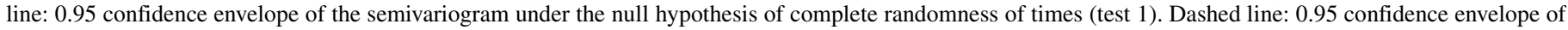

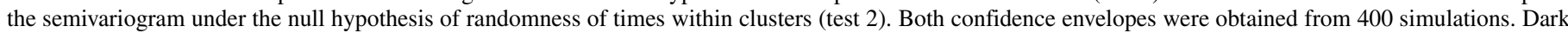
circles represent significant positive autocorrelation between times for test 2 .

to 12 months in most cases, and never exceeded 24 months. The incubation period is likely to be longer than indicated by these results because the contamination of new trees occurred before the neighboring symptomatic trees were removed. However, these values are comparable with those already reported, which were 3 to 9 months for 2- to 3-year-old coconut trees (7), and 7 to 15 months (33) or 6 to 24 months (8) for adult trees.

This study demonstrated that the observed spatial patterns of LY are at least partially caused by secondary spread of the disease. The variability in the intensity of aggregation and range of influence between fields is possibly due to differences of local ecological conditions. The systematic occurrence of clusters of diseased trees in every field in the study and of spatial autocorrelation at short distance between times of appearance of LY suggest that a more efficient control of the disease could be achieved by removing asymptomatic trees in the proximity of symptomatic ones. More experimentation is needed to identify the optimum distance for removal. Simulations based on different hypotheses of dispersion gradient and including economic considerations would help to prepare recommendations.

\section{ACKNOWLEDGMENTS}

We thank G. Thébaud for his valuable advice in methodology and critical analysis of the manuscript and three anonymous reviewers and the editor for valuable suggestions.

\section{LITERATURE CITED}

1. Ashburner, G. R., Cordova, I. I., Oropeza, C. M., Illingworth, R., and Harrison, N. A. 1996. First report of coconut lethal yellowing disease in Honduras. Plant Dis. 80:960.

2. Bachy, A., and Hoestra. 1958. Contribution à l'étude de la maladie de Kaïncopé du cocotier au Togo. Oléagineux 13:721-729.
3. Cardena, R., Villanueva, M., Santamaria, J., and Oropeza, C. 1991. Presence in Yucatan of mycoplasma-like organisms in Cocos nucifera L. palms showing yellowing disease symptoms. Can. J. Plant Pathol. 13:135-138.

4. Cliff, A. D., and Ord, J. K. 1981. Spatial Processes: Models and Applications. Pion, London.

5. Cochran, W. G. 1977. Sampling Techniques. John Wiley \& Sons, New York.

6. Cressie, N. A. C. 1993. Statistics for Spatial Data. John Wiley \& Sons, Inc., New York.

7. Dabek, A. J. 1975. The incubation period, rate of transmission and effect on growth of coconut lethal yellowing disease in Jamaica. J. Phytopathol. 84:1-9.

8. Dery, S. K., and Philippe, R. 1997. Preliminary study on the epidemiology of Cape St. Paul wilt disease of coconut in Ghana. Pages 255-260 in: Int. Workshop Lethal Yellowing-Like Dis. Coconut, Elmina, Ghana. S. Eden Green and F. Ofori, eds. NRI, Chatham.

9. Dollet, M., Giannotti, J., Renard, J., and Ghosh, S. 1977. Etude d'un jaunissement létal des cocotiers au Cameroun: La maladie de Kribi. Observations d'organismes de type mycoplasmes. Oléagineux 32:317322.

10. Ekpo, E., and Ojomo, E. 1990. The spread of lethal coconut diseases in West Africa: Incidence of Akwa disease (or bronze leaf wilt) in the Ishan area of Bendel State, Nigeria. Principes 34:143-146.

11. Escamilla-Bencomo, J., and Mora-Aguilera, G. 2003. Epidemiology of LY disease: Spatial patterns and incubation period and the application in an eradication program. In: XXX Congreso Nacional y V Internacional de la Sociedad Mexicana de Fitopatología. South Padre Island, TX.

12. Ferrandino, F. J. 2005. The explicit dependence of quadrat variance on the ratio of clump size to quadrat size. Phytopathology 95:452-462.

13. Góngora-Canul, C., Pérez-Hernández, O., Pech-Cauich, O., EscamillaBencomo, J., and Mora-Aguilera, G. 2004. Gradientes de diseminación del amarillamiento letal en cocotero (Cocos nucifera L.) en Yucatán, Mexico. Rev. Mex. Fitopatol. 22:370-376.

14. Gray, S. M., Moyer, J. W., and Bloomfield, P. 1986. Two-dimensional distance class model for quantitative description of virus-infected plant distribution lattices. Phytopathology 76:243-248.

15. Howard, F. W., Norris, R. C., and Thomas, D. L. 1983. Evidence of transmission of palm lethal yellowing agent by a planthopper, Mindus crudus (Homoptera: Cixiidae). Trop. Agric. 60:168-171. 
16. Hughes, G., and Madden, L. V. 1992. Aggregation and incidence of disease. Plant Pathol. 41:657-660.

17. Hughes, G., and Madden, L. V. 1993. Using the beta-binomial distribution to describe aggregated patterns of disease incidence. Phytopathology 83:759-763.

18. Lesnoff, M., and Lancelot, R. 2007. aod: Analysis of Overdispersed Data. $\mathrm{R}$ package version 1.1-24.

19. Madden, L. V., and Hughes, G. 1999. Sampling for plant disease incidence. Phytopathology 89:1088-1103.

20. McCoy, R. 1976. Comparative epidemiology of the lethal yellowing, Kaincopé and cadang-cadang diseases of coconut palm. Plant Dis. Rep. 60:498-502.

21. McCoy, R., Howard, F., Tsai, J., Donselman, H., Thomas, D., Basham, H., Atilano, R., Eskafi, F., Britt, L., and Collins, M. 1983. Lethal yellowing of palms. Agric. Exp. Stn. Bull. No. 834, University of Florida, Gainesville.

22. McCullagh, P., and Nelder, J. A. 1989. Generalized Linear Models. Chapman \& Hall, London.

23. Mpunami, A., Tymon, A., Jones, P., and Dickinson, M. 1999. Genetic diversity in the coconut lethal yellowing disease phytoplasmas of East Africa. Plant Pathol. 48:109-114.

24. Nelson, S. 1995. Spatiotemporal distance class analysis of plant disease epidemics. Phytopathology 85:37-43.

25. Nelson, S., and Campbell, C. 1993. Comparative spatial analysis of foliar epidemics on white clover caused by viruses, fungi, and a bacterium. Phytopathology 83:288-301.

26. Pérez-Hernández, O., Góngora-Canul, C., Medina-Lara, M. F., OropezaSalin, C., Escamilla-Bencomo, J. A., and Mora-Aguilera, G. 2003. Patrón espacio-temporal del amarillamiento letal en cocotero (Cocos nucifera L.) en Yucatán, México. Rev. Mex. Fitopatol. 22:231-238.

27. Peyrard, N., Calonnec, A., Bonnot, F., and Chadoeuf, J. 2005. Explorer un jeu de données sur grille par tests de permutation. Rev. Stat. Appl. 53:59-78.
28. Philippe, R., Nkansah Poku, J., Fabre, S., Quaicoe, R., Pilet, F., and Dollet, M. 2007. Search for the vector of Cape Saint Paul wilt (coconut lethal yellowing) in Ghana. Bull. Insectol. 60:179-180.

29. Philippe, R., Reignard, S., Descamps, S., Nkansah Poku, J., Quaicoe, R., Pilet, F., Fabre, S., and Dollet, M. 2009. Study on the transmission of coconut lethal yellowing in Ghana. Oléagineux, corps gras, lipids 16:102106.

30. Plavsic-Banjac, B., Hunt, P., and Maramorosch, K. 1972. Mycoplasmalike bodies associated with lethal yellowing disease of coconut palms. Phytopathology 62:298-299.

31. Purcell, A. H. 1982. Insect vector relationships with prokaryotic plant pathogens. Annu. Rev. Phytopathol. 20:397-417.

32. R Development Core Team. 2007. R: A Language and Environment for Statistical Computing. R Foundation for Statistical Computing, Vienna.

33. Romney, D. H. 1983. Brief review of coconut lethal yellowing. Indian Coconut J. 13:1-8.

34. Schuiling, M., and Mpunami, A. 1992. Lethal disease of coconut palm in Tanzania. I.- Comparison with other coconut diseases in East Africa. Oléagineux 47:511-515.

35. Schuiling, M., Mpunami, A., and Kaiza, D. 1992. Lethal disease of coconut palm in Tanzania. II. History, distribution and epidemiology. Oléagineux 47:516-522.

36. Steiner, K. 1976. Epidemiology of Kainkopé disease of coconut palms in Togo. Plant Dis. Rep. 60:613-617.

37. Thébaud, G., Peyrard, N., Dallot, S., Calonnec, A., and Labonne, G. 2005. Investigating disease spread between two assessment dates with permutation tests on a lattice. Phytopathology 95:1453-1461.

38. Williams, D. 1975. The analysis of binary responses from toxicological experiments involving reproduction and teratogenicity. Biometrics 31: 949-952. 